\title{
Untersuchungen zur Synchronisation in vivo: Temporäre Inhibition der DNA-Synthese durch Hydroxyharnstoff in normalen und malignen Säugerzellsystemen***
}

\author{
M. F. RAJEWSKY, D. F. HÜLSER und E. FabRICIUS \\ Max-Planck-Institut für Virusforschung, Abteilung Physikalische Biologie, Tübingen
}

Eingegangen am 29. Juli 1971

Studies on Synchronisation in vivo: Temporary Inhibition of DNA Synthesis in Normal and Malignant Mammalian Cell Systems with Hydroxyurea

Summary. The synchronous passage of proliferating cells through defined phases of the cell cycle is a prerequisite for the study of a number of problems associated with carcinogenesis and cancer therapy. It is particularly required for investigations of the differential sensitivity of mammalian cells in specific phases of the cell cycle to agents capable of initiating the process of malignant transformation, or causing cell death.

The present study is concerned with the in vivo synchronisation of different rat tissues (embryo; liver; spleen; transplantable BICR/MIR tumor) by temporary specific inhibition of DNA synthesis with hydroxyurea (HU). In the cell systems investigated, HU inhibited DNA synthesis rapidly and almost completely. On the other hand, the short half-life $\left(t_{1 / 2}\right)$ of the inhibitor in the organism permitted a termination of blocking periods without delay, as required for effective synchronisation. Following single or multiple doses of $\mathrm{HU}$, the $\mathrm{t}_{1 / 2}$ values for the HU concentration in BICR/M1R tumor tissue and rat blood were nearly identical. $t_{1 / 2}$ in rat and human blood exceeded the corresponding value for the mouse (13 min) by factors of about 2 and 8, respectively. In the rat cell systems investigated, DNA synthesis resumed when the $\mathrm{HU}$ concentration decreased below a level of $1-5 \times 10^{-5} \mathrm{moles} / 10^{3} \mathrm{~g}$ (exception: rat embryo; $\sim 2 \times 10^{4}$ moles $/ 10^{3} \mathrm{~g}$ ). The inhibitory effect of a specific blood concentration of $\mathrm{HU}$ on cellular DNA synthesis after in vivo administration of the inhibitor can be measured by the reduction of ${ }^{\mathrm{a}} \mathrm{H}$-thymidine incorporation in reference cells exposed to the respective blood plasma samples in vitro. Cytotoxic effects of $\mathrm{HU}$, which are often confined to cells blocked in $\mathrm{S}$, were particularly evident in cells of the lymphatic type. The BICR/MIR tumor served as a model cell system for the analysis of the kinetics of cell proliferation after single and multiple blocks of varying duration. The results show that partial synchronisation of proliferating cells in vivo can be obtained by temporary inhibition of DNA synthesis under controlled conditions.

Zusammenfassung. Die Bearbeitung einer Reihe von Problemstellungen der experimentellen und klinischen Krebsforschung setzt die Möglichkeit einer Synchronisation proliferierender Zellsysteme in vivo voraus. Dies gilt z. B. für die Frage, ob bei Säugerzellen als Funktion ihrer Position im Zellcyclus Empfindlichkeitsunterschiede vorhanden sind, und zwar sowohl hinsichtlich der Auslösbarkeit des Prozesses der malignen Transformation durch Cancerogene, als auch in bezug auf die Inaktivierbarkeit maligner Zellen durch cytocide Agentien oder ionisierende Strahlung.

In der vorliegenden Arbeit wird über Untersuchungen zur in vivo-Synchronisation verschiedener Gewebe (Embryo; Leber; Milz; transplantabler BICR/MIR-Tumor) der Ratte durch temporäre Blockade der DNA-Synthese mit Hydroxyharnstoff (HU) berichtet. HU inhibiert die DNA-Synthese in vivo spezifisch, rasch und nahezu vollständig. Das rasche

* Herrn Professor P. Dembowski $(\dagger)$ gewidmet.

** Die Arbeit wurde mit dem Gerhard-Domagk-Preis 1970 ausgezeichnet. 
Absinken der HU-Konzentration im Organismus unter den zur Hemmung der DNA-Synthese erforderlichen Schwellenwert gestattet eine hinreichend verzögerungsfreie Beendigung von DNA-Syntheseblocks, wie sie für eine effektive Synchronisation erforderlich ist. Nach ein- oder mehrmaliger Pulsapplikation von HU sind die Halbwertszeiten $\left(t_{1 / 2}\right)$ für die HU. Konzentration in BICR/M1R-Tumorgewebe und Blut annähernd gleich. Die $t_{1 / 2}-$ Werte im Blut von Maus (13 min), Ratte und Mensch verhalten sich wie etwa 1:2:8. In den gemessenen Zellsystemen der Ratte erfolgte die Aufhebung der DNA-Syntheseblocks bei Unterschreiten einer HU-Konzentration von $1-5 \times 10^{-5} \mathrm{Mol} / 10^{3} \mathrm{~g}$ (Ausnahme: Rattenembryo, $\sim 2 \times 10^{-4} \mathrm{Mol} / 10^{3} \mathrm{~g}$ ). Die Inhibitorwirkung einer bestimmten, im Blut gemessenen HU.

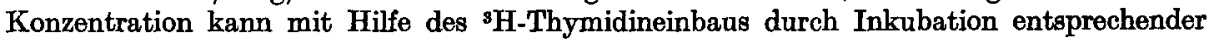
Blutplasmaproben mit Referenzzellen in vitro bestimmt werden. Cytotoxische Effekte von $\mathrm{HU}$, die wahrscheinlich vorwiegend auf blockierte S-Zellen beschränkt sind, waren besonders deutlich bei Zellen vom lymphatischen Typ. Als Modellsystem für die Analyse der Proliferationskinetik nach ein- und mehrmaligen DNA-Syntheseblocks von verschiedener Dauer diente der BICR/MIR-Tumor. Die Ergebnisse zeigen, daß durch Anwendung eines Inhibitors der DNA-Synthese vom Typ des HU unter kontrollierten Bedingungen eine partielle Synchronisation proliferierender Zellen in vivo erreicht werden kann.

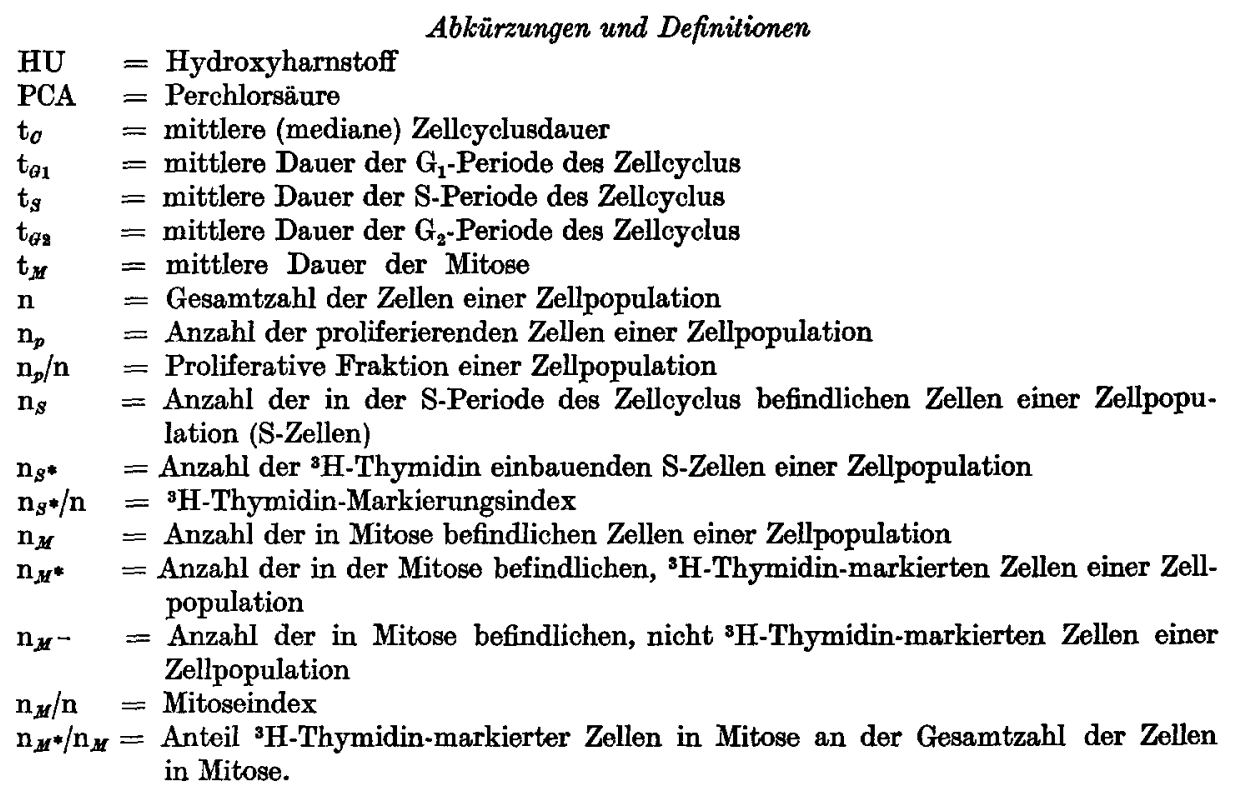

Für die Bearbeitung zell- und molekularbiologischer Problemstellungen ist es häufig eine Vorbedingung, daß die Zellen einer proliferierenden Zellpopulation definierte Abschnitte des Zellcyclus synchron durchlaufen. So ist auf dem Gebiet der Krebsforschung beispielsweise die Frage zu prüfen, ob bei Säugerzellen als Funktion ihrer Position im Zellcyclus Empfindlichkeitsunterschiede vorhanden sind, und zwar sowohl für die Auslösbarkeit des Prozesses der malignen Transformation durch cancerogene Faktoren (Rajewsky, 1970 [2]) als auch für die Inaktivierbarkeit maligner Zellen durch cytocide Agentien (Mauro u. Madoc-Jones, 1970) oder ionisierende Strahlung (Sinclair, 1968).

Während zur Synchronisation permanenter Zellstämme in Gewebekultur experimentelle Verfahren zur Verfügung stehen (Sinclair, 1969; Stubblefield, 1968), sind Möglichkeiten zur in vivo Synchronisation proliferierender Säugerzellsysteme 
bisher nicht systematisch untersucht worden. Die Ausarbeitung entsprechender Methoden ist jedoch von Interesse, da es oft nicht zulässig ist, Schlußfolgerungen für das Verhalten von Zellen im intakten Gewebe alleine aus Befunden an Zellkulturen zu ziehen, die vielen der im Organismus wirksamen Kontrollmechanismen nicht unterliegen. Hinzu kommt, daß eine Synchronisation maligner Zellen in vivo unter Umständen im Rahmen der Krebstherapie nicht ohne Bedeutung ist (Mauro u. Madoc-Jones, 1970; Rajewsky, 1970 (2)).

Die Ausnutzung der in vivo auf Grund biologischer Regulationsmechanismen auftretenden Synchronie [z. B. diurnale Schwankungen der Mitoseaktivität in bestimmten Geweben (Pilgrim u. Mitarb., 1965) oder Auslösung von DNASynthese- und Mitosemaxima in regenerationsfähigen (Bucher, 1963) oder hormonell stimulierbaren (Bresciani, 1965) Zellsystemen] ist nur selten möglich.

Grundsätzlich können synchrone Zellpopulationen entweder dadurch gewonnen werden, daß man aus einer asynchronen Population eine Subpopulation abtrennt, die sich in einem kurzen Abschnitt des Zelleyclus befindet (z. B. in der Mitose), oder daß man das Durchlaufen bestimmter Abschnitte des Zellcyclus zeitweise blockiert (z. B. DNA-Synthese oder Mitose). Während die erstgenannte Möglichkeit unter in vivo Bedingungen mit Ausnahme spezieller Fälle (z. B. selektive Markierung der Zellen in der S-Periode des Zellcyclus mit radioaktivem Thymidin) praktisch ausscheidet, bietet sich für den letzteren Fall die Anwendung spezifischer chemischer Inhibitoren für makromolekulare Synthesen an, die auf definierte Abschnitte des Zellcyclus beschränkt sind. So kann eine temporäre, spezifische Inhibition der DNA-Synthese (mit oder ohne Abtötung der arretierten S-Zellen) zu einer partiellen Synchronie führen, und zwar dadurch, daß während des Blocks $G_{2}$ und $G_{1}-Z$ Zellen der asynchronen Population im $\mathrm{G}_{1}$-S-Übergangsbereich auflaufen, und nach Aufheben des Blocks dann synchron die S-Periode des Zellcyclus passieren (s. auch Abb. 7 u. 8). Voraussetzung für die Anwendbarkeit eines chemischen Inhibitors zur Synchronisation unter in vivo-Bedingungen ist jedoch, daß nicht nur die Etablierung des Blocks, sondern auch seine Aufhebung rasch und in reproduzierbarer Weise möglich ist.

In der vorliegenden Arbeit wurde versucht, mit Hilfe von Hydroxyharnstoff, einem spezifischen und hochwirksamen Inhibitor der DNA-Synthese, eine Synchronisation verschiedener normaler und maligner Säugergewebe zu erreichen. Uber erste, an einem malignen Zellsystem der Ratte durchgeführte Messungen ist bereits berichtet worden (Rajewsky, 1968; Rajewsky, $1970(1)$ ). Die bisher erzielten Ergebnisse sollen nunmehr im Zusammenhang dargestellt werden.

\section{Material und Methoden}

\section{Tiermaterial}

Es wurden weibliche Ratten der Stämme Marshall1 und BD IX (Druckrey, 1971) sowie männliche Mäuse des Stammes Balb/c2 aus eigener Zucht verwendet.

\section{Untersuchte Zellsysteme}

a) BICR/MIR-Tumor (adulte Marshall-Ratte (o)),

b) Leber (adulte Marshall-Ratte (o)),

1 Institute of Cancer Research, London.

2 R. B. Jackson Memorial Laboratory, Bar Harbor, Maine. 
c) Milz (adulte Marshall-Ratte ())),

d) Rattenembryo (BD IX-Ratte, 18. Tag der Gravidität).

Der BICR/MIR-Tumor der weiblichen Marshall-Ratte ist ein solider, subcutan transplantabler Mammatumor, der 1955 bei einem weiblichen Tier des gleichen Stammes spontan entstand (ursprüngliche Bezeichnung: BICR/MI (Steel u. Mitarb., 1966)) und seither auf weiblichen Marshall-Ratten passagiert wurde. Die seit 1965 in unserem Laboratorium gehaltene Linie trägt die Bezeichnung BICR/MIR. Alle Versuche wurden an BICR/MIR-Tumoren von $0,5-1,0 \mathrm{~g}$ Frischgewicht durchgeführt, die auf $200-250 \mathrm{~g}$ schweren Tieren gehalten wurden.

Die proliferativen Eigenschaften des BICR/MIR-Tumors wurden autoradiographisch analysiert. Dabei ließen Dauermarkierungsversuche (Injektion von ${ }^{3} \mathrm{H}-$ Thymidin in Abständen von 6 Std für die Dauer von 48 Std) auf eine Proliferative Fraktion $\left(n_{p} / n\right)$ von 0,9 bis 1,0 schließen. Die mittlere Dauer der einzelnen Zellcyclusperioden wurde mit Hilfe der „Markierte-Mitosen-Methode" (Quastler u. Sherman, 1959) autoradiographisch bestimmt (Abb. 1).

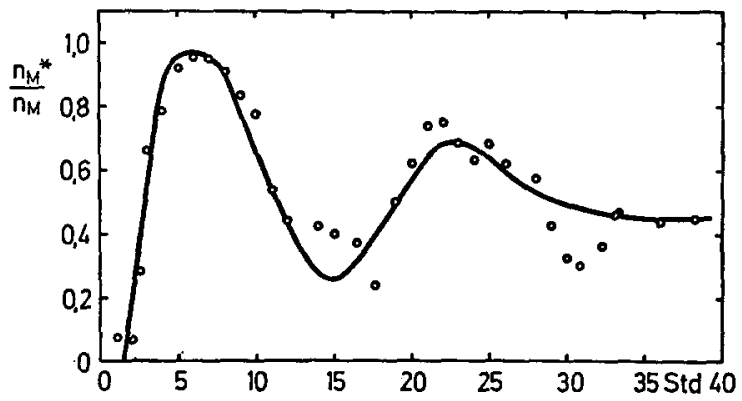

Abb. 1. Zellcyclusanalyse für die proliferierenden Zellen des BICR/M1R-Tumors der MarshallRatte mit Hilfe der Markierte-Mitosen-Methode. Die Meßpunkte sind Mittelwerte aus mehreren Bestimmungen für jeweils einen Tumor. Die gezeichnete Kurve wurde mit Hilfe eines optimierenden Computerprogramms (Barrett, 1966; Steel u. Hanes, 1971) berechnet. Ordinate: Verhältnis der ${ }^{3} \mathrm{H}$-markierten Mitosen $\left(\mathrm{n}_{\mathbf{x}^{*}}\right)$ zur Gesamtzahl der Mitosen $\left(\mathrm{n}_{\mathbf{z}}\right)$. Abszisse: Zeit nach ${ }^{3} \mathrm{H}$-Thymidin-Puls (Std). (Nach Rajewsky [1970, (1)] mit Genehmigung von Academic Press, Inc., New York-London)

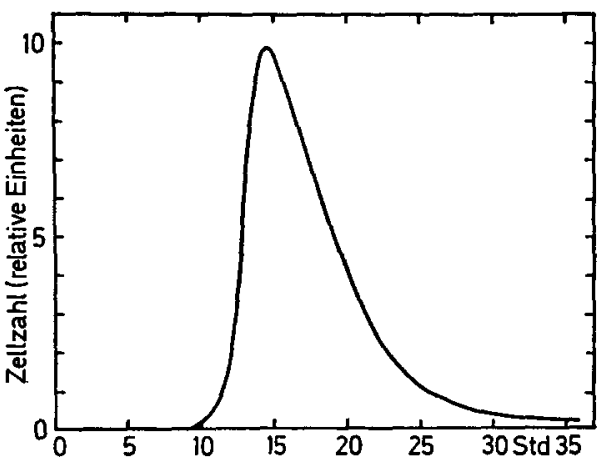

Abb. 2<smiles>NC(=O)NO</smiles>

Abb. 3

Abb. 2. Mit Hilfe eines Computerprogramms (Barrett, 1966; Steel u. Hanes, 1971) berechnete Verteilung der Zellcyclusdauern ( $\left.t_{c}\right)$ für die proliferierenden Zellen des BICR/M1R-Tumors der Marshall-Ratte. (Nach Rajewsky [1970, (1)] mit Genehmigung von Academic Press, Inc., New York-London)

Abb. 3. Hydroxyharnstoff. (Dresler u. Stein, 1869) 
Tabelle 1. Zellcyclusparameter der transplantablen BICR/M1R- und BICR/M1-Tumoren der Marshall-Ratte

\begin{tabular}{|c|c|c|}
\hline Zelloyclusparameter & BICR/M1R & $\mathrm{BICR} / \mathrm{M1}$ \\
\hline$t_{G_{1}}( \pm$ Standardabweichung $)$ & $5,6 \pm 0,6 \mathrm{Std}$ & $8,3 \pm 3,6 \mathrm{Std}$ (Steel, 1969) \\
\hline $\mathrm{t}_{\boldsymbol{s}}$ (士 Standardabweichung) & $10,2 \pm 5,1 \mathrm{Std}$ & $7,9 \pm 2,4$ Std (Steel, 1969) \\
\hline $\mathbf{t}_{\boldsymbol{G}_{3}}$ (士 Standardabweichung) & $3,0 \pm 0,9 \mathrm{Std}$ & $3.0 \pm 1,3 \mathrm{Std}$ (Steel, 1969) \\
\hline$t_{o}$ (Medianwert) & $17,7 \mathrm{Std}$ & 17,6 Std (Steel, 1969) \\
\hline $\begin{array}{l}\text { Proliferative Fraktion }\left(\mathrm{n}_{\mathrm{p}} / \mathrm{n}\right) \\
\text { in Tumoren von } 0,5-1,0 \mathrm{~g} \\
\text { Frischgewicht }\end{array}$ & $\sim 0,9$ & $\sim 0,9$ (Steel u. Mitarb., 1966) \\
\hline $\begin{array}{l}{ }^{3} \mathrm{H}-\text { Thymidin-Markierungsindex } \\
\left(\mathrm{n}_{s}^{*} / \mathrm{n}\right) \text { ( } \pm \text { Standardabweichung) }\end{array}$ & $0,356 \pm 0.053$ & $0,342 \pm 0,044$ (Steel u. Mitarb., \\
\hline $\begin{array}{l}\text { Mitoseindex }\left(\mathrm{n}_{M} / \mathrm{n}\right) \\
( \pm \text { Standardabweichung) }\end{array}$ & $0.019 \pm 0.004$ & nicht angegeben \\
\hline
\end{tabular}

Dabei wurden die Meßdaten mit einer von Barrett (1966) angegebenen und von Steel $u$. Hanes (1971) weiterentwickelten optimierenden Computermethode analysiert. Abb. 2 zeigt die mit Hilfe dieser Methode berechnete Verteilung der Zellcyclusdauer $\left(t_{\sigma}\right)$ für eine BICR/MIR-Zellpopulation. In Tab. 1 sind die Zellcyclusparameter des BICR/MIR-Tumors sowie die entsprechenden, für die Original-Tumorlinie BICR/MI gemessenen Werte (Steel, 1969) wiedergegeben.

\section{Hydroxyharnstoff}

Hydroxyharnstoff (HU) (Abb. 3) wurde 1869 von Dresler u. Stein erstmalig synthetisiert; seine inhibitorische Wirkung auf die DNA-Synthese wurde 1964 von Young u. Hodas an HeLa-Zellen erstmalig beobachtet. Seither hat sich die Substanz als einer der wirksamsten spezifischen Inhibitoren der DNA-Synthese von Säugerzellen erwiesen (Farber u. Baserga, 1969; Kim u. Mitarb., 1967; Pfeiffer u. Tolmach, 1967; Philips u. Mitarb., 1967; Rajewsky, 1968; Rajewsky, 1970 (1); Rosenkranz u. Mitarb., 1969; Schwartz u. Mitarb., 1965; Sinclair, 1965; Süss u. Maurer, 1968; Young u. Hodas, 1964). Im Vergleich zur DNA. Synthese des Zellkerns ist die Synthese cytoplasmatischer DNA durch HU weniger leicht hemmbar (Vesco u. Penman, 1969). HU-Konzentrationen, welche die DNA-Synthese inhibieren, scheinen die RNA- und Proteinsynthese nicht zu beeinflussen (Pollak u. Rosenkranz, 1967; Young u. Hodas, 1964). Dagegen hemmt HU bei HeLa-Zellen auch die Histonsynthese (Mueller, 1969).

Die molekularen Mechanismen, welche der Hemmung der zellulären DNA-Synthese durch HU sowie seiner offenbar weitgehend auf Zellen in der S-Periode des Zellcyclus beschränkten cytotoxischen Wirkung zugrunde liegen, sind noch nicht vollständig geklärt. Verschiedene Autoren haben Hinweise dafür gefunden, daB HU die Umwandlung von Cytidylsäure zu Desoxycytidylsäure blockiert (Adams u. Lindsay, 1967; Gale, 1968; Young u. Hodas, 1964; Young u. Mitarb., 1967 (1); Young u. Mitarb., 1967 (2); aber siehe auch Pollak u. Rosenkranz, 1967; Rosenkranz u. Carr, 1970; Yarbro, 1968), und zwar durch Inhibition des Enzyms B 2 des Ribonucleotid-Reduktase-Systems (Krakoff u. Mitarb., 1968; s. Abb. 4). Andererseits können aber direkte Wirkungen auf die DNA (Rosenkranz, 1970; Rosenkranz u. Jacobs, 1968; Rosenkranz u. Mitarb., 1968; Rosenkranz u. Mitarb., 1969), oder die Beeinflussung anderer, die DNA-Synthese regulierender Enzyme (Jacobs, 1968; Rosenkranz u. Jacobs, 1968) nicht ausgeschlossen werden. Es muß die Möglichkeit in Betracht gezogen werden, da $\beta$ aus $\mathrm{HU}$ unter in vivo-Bedingungen ein oder mehrere aktive Metabolite entstehen, und die Substanz auf diesem Wege mit mehreren cellulären Stoffwechselprozessen interferiert. So haben Rosenkranz u. Mitarb. (Rosenkranz, 1970; Rosenkranz u. Mitarb., 1969) gefunden, daß gealterte HU-Lösungen die Substanzen Isohydroxyharnstoff, N,O-Dicarbamoylhydroxylamin sowie eine noch unidentifizierte Nitrosoharnstoffverbindung enthalten. Die biologischen Wirkungen dieser Verbindungen werden gegenwärtig analysiert; 
sie scheinen bei $E$. coli unter anderem eine Degradation der DNA zu bewirken (Rosenkranz, 1970; Rosenkranz u. Mitarb., 1969).

Im Säugerorganismus wird HU zum großen Teil in Harnstoff umgewandelt, und zwar offenbar vorwiegend durch enzymatische Reduktion in der Leber (Adamson u. Mitarb., 1965 (1); Colvin u. Bono, 1970).

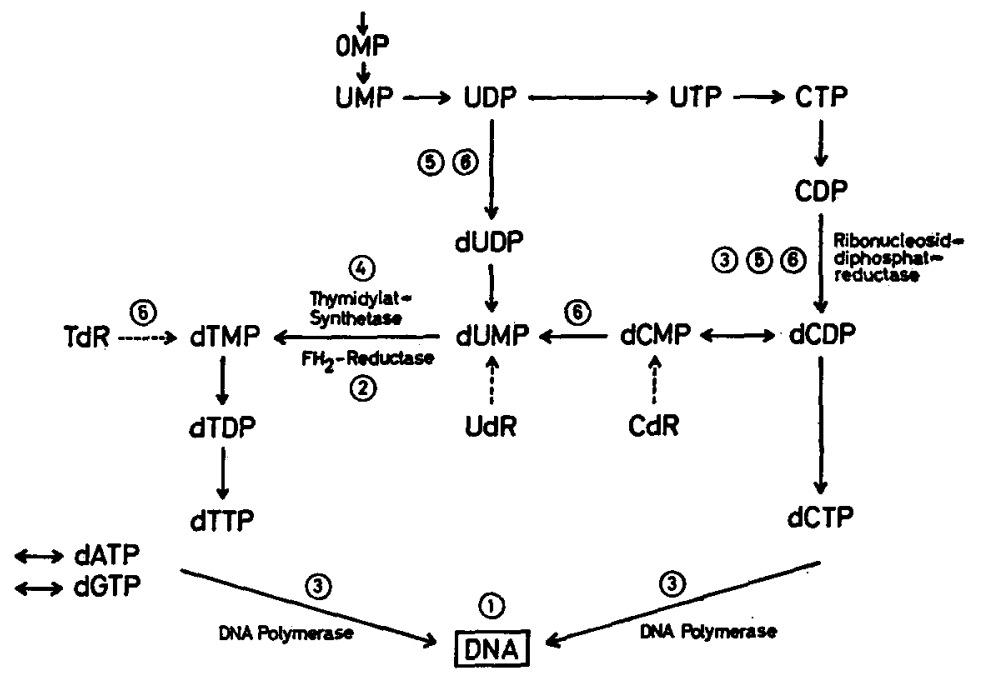

Abb. 4. Schematische Darstellung des Pyrimidinnucleotid-Stoffwechsels bei der DNA-Synthese sowie der wahrscheinlichen Angriffspunkte einiger Inhibitoren der DNA-Synthese. - „, „de novo"-Stoffwechselwege, .... ,salvage"-Stoffwechselwege. 1 Alkylierende Substanzen, 2 Amethopterin, 3 -D-Arabinofuranosylcytosin (Ara-C), 4 5-Fluoro-2'-desoxyuridin (FUDR), 5 Hydroxyharnstoff (HU), 6 therschuß von Thymidin, Desoxyadenosin

Die akute Toxicität von HU bei Laboratoriumstieren ist gering $\left(\mathrm{LD}_{50} \approx 7 \mathrm{mg} / \mathrm{g}\right.$ Körpergewicht) (Adamson u. Mitarb., 1965 (2)). So traten in eigenen Versuchen, in denen adulte männliche Ratten des Marshall-Stammes über einen Zeitraum von 120 Tagen alle 12 Tage 2 Dosen von je $0,5 \mathrm{mg} \mathrm{HU} / \mathrm{g}$ Körpergewicht (Zeitintervall $5 \mathrm{Std}$ ) erhielten, keine sichtbaren toxischen Effekte auf (Rajewsky, 1970 (1)). Eine cancerogene Wirkung von HU wurde bisher nicht beobachtet.

Cytotoxische Wirkungen von HU, die zu einem Verlust der reproduktiven Kapazität der Zelle führen, scheinen weitgehend auf Zellen in der S-Periode des Zellcyclus beschränkt zu sein (Kim u. Mitarb., 1967; Philips u. Mitarb., 1967; Rajewsky, 1970 (1); Sinclair, 1965; Thurman u. Mitarb., 1963). Diese Effekte werden im allgemeinen durch HU-Konzentrationen hervorgerufen, welche die zur Hemmung der DNA-Synthese erforderlichen übersteigen (Farber u. Baserga, 1969; Kim u. Mitarb., 1967; Pfeiffer u. Tolmach, 1967; Sinclair, 1965). Untersuchungen an Zellkulturen haben gezeigt, daß eine Abnahme der Utberlebenswahrscheinlichkeit der Zellen auch erfolgt, wenn S-Zellen, oder Zellen, die im $\mathrm{G}_{1}$-S-Utbergangsbereich aufgestaut wurden, für sehr lange Perioden der Wirkung eines Inhibitors der DNASynthese ausgesetzt werden (Cole u. Strauss, 1970; Eidinoff u. Rich, 1959; Kim u. Mitarb., 1967; Rueckert u. Mueller, 1960). Dieser Effekt ist wahrscheinlich durch eine protrahierte Dissoziation makromolekularer Synthesen bedingt ("unbalanced growth"). Für eine solche Deutung spricht auch die teilweise Reversibilität des Effekts durch gleichzeitige Anwendung eines Inhibitors der Proteinsynthese (Kim u. Mitarb., 1968).

Der verwendete Hydroxyharnstoff wurde von den Firmen Nutritional Biochemicals Corp., USA, und Schuchardt GmbH \& Co., München sowie vom Squibb Institute for Medical Research, USA, bezogen. Die Applikation der Substanz erfolgte stets intraperitoneal in steriler und pyrogenfreier $0,9 \% \mathrm{NaCl}$-Lösung. 


\section{Hydroxyharnstof-Nachweis}

Bei den vorliegenden Untersuchungen war es notwendig, die HU-Konzentration in verschiedenen Säugergeweben und Blut zu bestimmen. Hierfür war eine Nachweismethode zu wählen, die für Harnstoff, das Hauptabbauprodukt des HU, keine positive Reaktion ergibt. Als geeignet erschienen Methoden zur Bestimmung von Hydroxamaten (Bergmann u. Segal, 1956; Nery, 1966; Philips u. Mitarb., 1967), die entsprechend modifiziert und den gegebenen experimentellen Erfordernissen angepaßt wurden (Fabricius u. Rajewsky, 1971).

Bei der Jodoxydation von Hydroxamaten entsteht Nitrit, das Sulfanilsäure diazotiert. Nach Reduktion des überschüssigen Jods mit Natriumthiosulfat und Zugabe von $\alpha$-Naphthyläthylendiamindihydrochlorid, kuppelt dieses mit der diazotierten Sulfanilsäure zu einem roten Farbstoff. Die Absorption dieses Farbstoffs wird bei $540 \mathrm{~nm}$ im Spektralphotometer gemessen. Wie aus der in Abb. 5 gezeigten Standard-Kurve hervorgeht, kann auf diesem

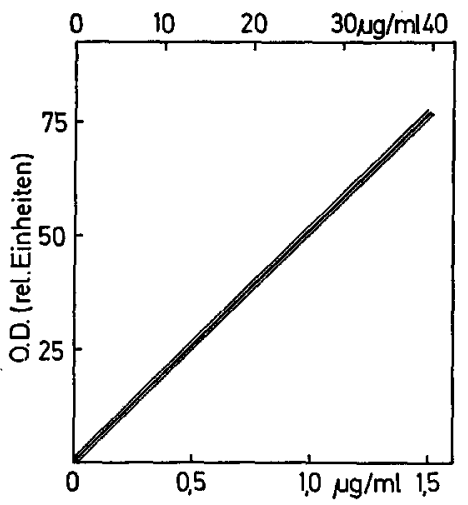

Abb. 5. Standardkurve für die Hydroxyharnstoffbestimmung. Bestimmungsmethode siehe „Material und Methoden". Ordinate: Optische Dichte bei $\lambda=540 \mathrm{~nm}$ (relative Einh.). Abszissen, unten: HU-Endkonzentration der Meßprobe $(\mu \mathrm{g} / \mathrm{ml})$, oben: HU-Konzentration der Ausgangsprobe $(\mu \mathrm{g} / \mathrm{ml}) .95 \%$ der Mittelwerte aus 8 unabhängigen Meßreihen liegen innerhalb des zusammen mit der Standardkurve angegebenen Streubandes

Wege bei einer optischen Dichte von 0,05 noch eine HU-Konzentration von $0,094 \mu \mathrm{g} / \mathrm{ml}$ nachgewiesen werden. Da die Herstellung der endgültigen Meßproben eine Verdünnung der ursprünglichen Blut- oder Gewebeproben um den Faktor 26,5 erforderte, lagen die entsprechenden Nachweisgrenzen für Blut und Gewebe bei $2,5 \mu \mathrm{g} \mathrm{HU} / \mathrm{ml}$, bzw. 2,5 $\mu \mathrm{g} \mathrm{HU} / \mathrm{g}$.

Im einzelnen wurden die Blut- und Gewebeproben wie folgt zur HU-Analyse aufgearbeitet:

a) Blut: $1 \mathrm{ml}$ Blut wurde mit $4 \mathrm{ml} \mathrm{H}_{2} \mathrm{O}$ und nach 1 min mit $5 \mathrm{ml} 1 \mathrm{~m}$ PCA gemischt und nach $10 \mathrm{~min}$ bei $4^{\circ} \mathrm{C}$ und $30000 \mathrm{xg}$ für $20 \mathrm{~min}$ zentrifugiert. Der Utberstand wurde durch mit PCA $\left(0,5 \mathrm{~m}\right.$ ) gewaschene Selecta (Nr. 595 1/2)-Filter filtriert und bei $-20^{\circ} \mathrm{C}$ aufbewahrt.

b) Gewebe: $1 \mathrm{~g}$ Gewebe wurde mit $4 \mathrm{ml} \mathrm{H}_{2} \mathrm{O}$ versetzt und bei mittlerer Umdrehungszahl und Eiskühlung für $20 \mathrm{sec}$ mit einem Ultraturrax (Fa. Janke und Kunkel KG, Staufen) homogenisiert. Dem Homogenat wurden $5 \mathrm{ml} 1 \mathrm{~m}$ PCA zugesetzt. Weitere Behandlung der Proben siehe unter a (Blut).

c) Analyse der Filtrate: $\mathrm{Zu} 2 \mathrm{ml}$-Aliquoten der Filtrate sowie der in 0,5 m PCA hergestellten Standards wurden nacheinander $1 \mathrm{ml}$ Puffer $\left(96,6 \mathrm{ml} 0,5 \mathrm{~m} \mathrm{Na} \mathrm{NaO}_{4}+17,8 \mathrm{ml}\right.$ $\left.1,5 \mathrm{~m} \mathrm{NaH} \mathrm{PO}_{4}+85,6 \mathrm{ml} \mathrm{H} \mathrm{H}_{2} \mathrm{O}\right), 0,1 \mathrm{ml} \mathrm{41 \%} \mathrm{NaOH}$ und $1 \mathrm{ml} 1 \%$ Sulfanilsäure zugegeben. Der pH-Wert dieses Gemisches muß zwischen 6,9 und 7,3 liegen. Nach Zugabe von 0,1 ml $0,1 \mathrm{n} \mathrm{I}_{2}$ in $2,5 \% \mathrm{KI}$ und einem anschließenden Zeitintervall von $3 \mathrm{~min}$ wurden $0,1 \mathrm{ml} 0,1 \mathrm{~m}$ frisch angesetztes Natriumthiosulfat und, sofort nach Mischen, $1 \mathrm{ml}$ einer frischen $\alpha$-Naph- 
thyläthylendiamin-dihydrochlorid-Lösung (100 mg $\alpha$-Naphthyläthylendiamin-dihydrochlorid $+17,5 \mathrm{ml} 12 \mathrm{n} \mathrm{HCl}+\mathrm{H}_{2} \mathrm{O}$ ad $100 \mathrm{ml}$ ) zugesetzt. Um eine maximale Farbentwicklung $\mathrm{zu}$ gewährleisten, wurde das Gemisch vor der Absorptionsmessung 20 min stehengelassen.

Bestimmung der Halbwertszeiten für den Abfall der HU-Konzentration in Geweben und Blut

Die zu verschiedenen Zeitpunkten nach Applikation von HU mit der oben beschriebenen Nachweismethode gemessenen HU-Konzentrationen wurden als Funktion der Zeit im halblogarithmischen Maßstab aufgetragen. Mit den Meßwerten wurde eine Regressionsanalyse durchgeführt und die Halbwertszeiten $\left(t_{1 / 2}\right)$ aus den ermittelten Geradengleichungen berechnet.

\section{Messung der ${ }^{3} H$-Alktivität und Autoradiographie nach ${ }^{3} H$-Thymidin-Markierung}

Die Pulsmarkierung DNA-synthetisierender Zellen erfolgte durch intraperitoneale Injektion von Thymidin-methyl- ${ }^{3} \mathrm{H}$ (Radiochemical Centre, Amersham, England, bzw. Farbwerke Hoechst AG, Frankfurt/M.) einer spezifischen Aktivität von $15 \mathrm{Ci} / \mathrm{mM}$, in einer Verdünnung von $200 \mu \mathrm{Ci} / \mathrm{ml}$ in steriler, pyrogenfreier $0,9 \% \mathrm{NaCl}$-Lösung. Während für die autoradiographische Bestimmung des Prozentsatzes markierter Mitosen beim BICR/MRRTumor eine Dosis von $1 \mu \mathrm{Ci} / g$ Körpergewicht verwendet wurde, betrug die Dosis bei allen übrigen Versuchen $0,5 \mu \mathrm{Ci} / \mathrm{g}$ Körpergewicht.

In allen Versuchen (mit Ausnahme der Markierte-Mitosen-Bestimmungen) wurden die zu untersuchenden Gewebe $30 \mathrm{~min}$ nach ${ }^{3} \mathrm{H}$-Thymidin-Pulsmarkierung entnommen und bei $4^{\circ} \mathrm{C}$ im 10 fachen Volumen Äthanol-Eisessig (3:1) fixiert. Die Fixationslösung wurde zweimal in Abständen von 24 Std erneuert, bevor die Präparate in $4 \%$ gepufferte Formaldehydlösung überführt wurden. Von den zur autoradiographischen Auswertung vorgesehenen Präparaten wurden nach Einbettung in Paraplast (Shandon Scientific Co.) $4 \mu$-Mikrotomschnitte angefertigt, die Feulgen-gefärbt und nach der Dipping-Methode mit Ilford K5-Kernemulsion beschichtet wurden. Die Expositionszeit betrug 4-6 Wochen bei $4^{\circ} \mathrm{C}$. Anschließend wurden die Autoradiogramme in Kodak D 19b-Entwickler entwickelt und in Kodak Unifix fixiert. Die Anzahl von Silberkörnern/Kern, von der an ein Zellkern als markiert gewertet wurde, betrug entsprechend den jeweiligen Backgroundbestimmungen 3-6. Die Meßpunkte bei den Markierte-Mitosen-Versuchen basieren auf der Auswertung von $\geqq 150$ Mitosen je Meßpunkt. Bei den Synchronisationsexperimenten wurden etwa 200 markierte Zellkerne je Meßpunkt ausgezählt.

In einigen Versuchen wurde anstelle der autoradiographischen Auswertung eine Direktmessung der gebundenen ${ }^{3} \mathrm{H}$-Aktivität mit Hilfe des Flüssigkeitsszintillations-Spektrometers durchgeführt. Hierzu wurden entweder $10 \mu$-Mikrotomschnitte gleicher Flächengröße auf Millipore-Filter aufgebracht, entparaffiniert und in Toluol-Szintillatorlösung (5 g PPO + $0,3 \mathrm{~g}$ POPOP + 11 Toluol) gemessen, oder Gewebeproben nach Vakuumtrocknung bis zur Gewichtskonstanz mit Hilfe einer nach Kalberer u. Rutschmann (1961) modifizierten Methode der trockenen Oxydation im geschlossenen Kolben verbrannt. Das bei der Verbrennung gebildete HTO wurde in Methanol absorbiert und die ${ }^{3} \mathrm{H}$-Aktivität eines Aliquots nach Mischung mit Szintillatorlösung bestimmt. Alle Proben wurden bis zum Auflaufen von $10^{4}$ Impulsen gemessen und die Zählausbeute mit Hilfe der Kanalverhältnismethode (Bush, 1963) bestimmt.

\section{Untersuchungen an Zellkulturen}

In einigen Versuchen wurden HU-haltige Blutplasmaproben zur Messung ihrer Hemmwirkung auf die DNA-Synthese mit permanenten Zellstämmen (z. B. HeLa-Zellen) in Monolayerkultur inkubiert. Zum Zeitpunkt der Messung (48 Std nach Aussaat einer Startzellzahl von $4 \times 10^{4} / 35 \mathrm{~mm}$-Falcon-Plastikkulturschale) befanden sich die Zellen in der exponentiellen Wachstumsphase. Bei den mit gleicher Zellzahl/Kulturschale in einer Atmosphäre von $5 \%$ $\mathrm{CO}_{2}$ in Luft bei $37^{\circ} \mathrm{C}$ gezüchteten Kulturen wurde das Medium (2 ml Eagle's Medium, Dulbecco Modifikation, mit $10 \%$ Kälberserum) gegen $1 \mathrm{ml}$ Blutplasma ausgetauscht und für $30 \mathrm{~min}$ inkubiert. Anschließend wurde ${ }^{3} \mathrm{H}$-Thymidin $(1 \mu \mathrm{Ci} / \mathrm{Kulturschale} \mathrm{in} 10 \mu \mathrm{l}$ $0,9 \% \mathrm{NaCl}$-Lösung; spez. Aktivität $=15 \mathrm{Ci} / \mathrm{mM}$ ) zugesetzt und für weitere $30 \mathrm{~min}$ inkubiert. Das Blutplasma wurde dann abgesaugt, die Kulturen 2 mal mit Hanks-Lösung $(+10 \mathrm{mg}$ Thymidin $\left./ 1 ; 4^{\circ} \mathrm{C}\right)$ gewaschen, die Zellen mit $0,25 \%$ Trypsinlösung $(+10 \mathrm{mg}$ Thymidin $/ 1$; $37^{\circ} \mathrm{C} ; 10 \mathrm{~min}$ ) abgelöst und die Lösung durch Milliporefilter (Porenweite 0,45 $\mu \mathrm{m}$; Millipore Filter GmbH, Neu-Isenburg) gesaugt. Zur Entfernung der säurelöslichen Fraktion wurden 
die auf den Milliporefiltern abgelagerten Zellen 2 mal mit $5 \%$ Trichloressigsäure $\left(4^{\circ} \mathrm{C}\right.$ ) nachgewaschen. Nach Trocknung der Filter wurde ihre ${ }^{3} \mathrm{H}$-Aktivität im FlüssigkeitsezintillationsSpektrometer gemessen.

\section{Partielle Hepatektomie}

Einige Messungen wurden an weiblichen Ratten des Marshall-Stamms durchgeführt, die zuvor teilhepatektomiert $(68 \%)$ worden waren. Die Operation erfolgte in Äthernarkose nach der von Higgins u. Anderson (1931) angegebenen Methode.

\section{Ergebnisse}

Die Anwendung von $\mathrm{HU}$ zur in viva-Synchronisation durch temporäre Inhibition der DNA-Synthese (vgl. Abb. 6 u. 7) macht eine genaue Bestimmung der

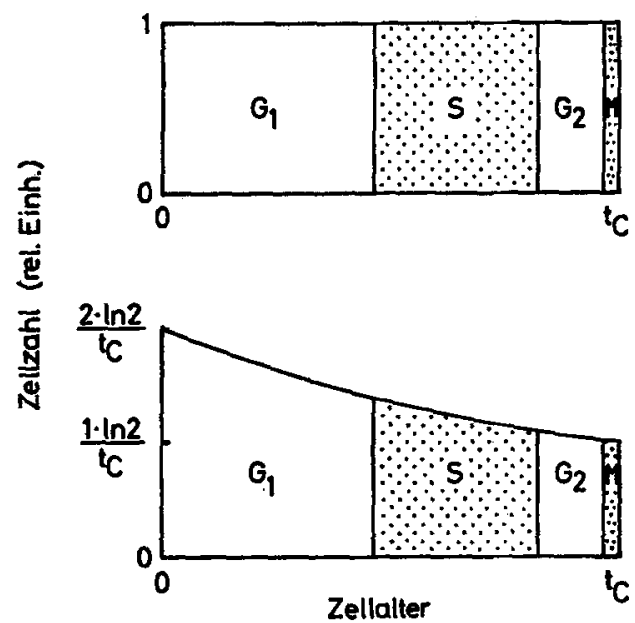

Abb. 6. Diagrammatische Darstellung der Zellaltersverteilung für proliferierende Zellpopulationen im Steady-State (oben) und im exponentiellen Wachstum (unten). Ordinate:

Zellzahl (relative Einh.). Abszisse: Zellalter

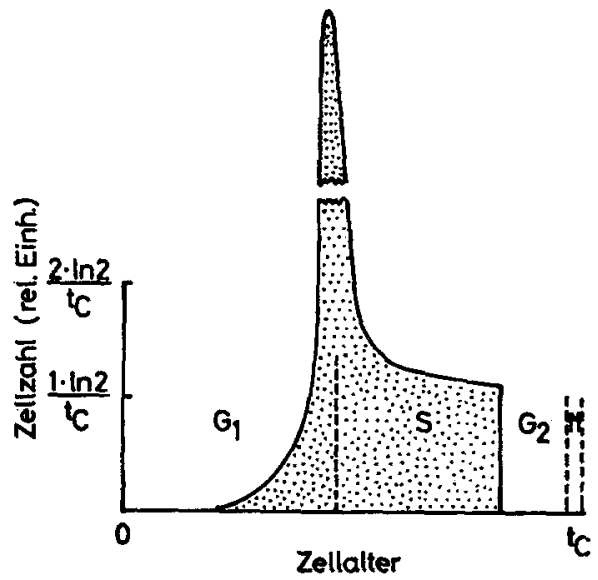

Abb. 7. Diagrammatische Darstellung der Zellaltersverteilung einer exponentiell proliferierenden Zellpopulation nach temporärer Blockade der DNA-Synthese. Ordinate: Zellzahl (relative Einh.). Abszisse: Zellalter 
in vivo-Abfallkinetik der Substanz notwendig. Diese ist erforderlich, um die zeitliche Änderung der HU-Konzentration in bestimmten Zellsystemen mit Ausmaß und Dauer der DNA-Synthesehemmung korrelieren zu können. Nur eine hinreichend kurze in vivo-Halbwertszeit $\left(t_{1 / 2}\right)$ und das damit verbundene rasche Unterschreiten einer kritischen unteren Hemmkonzentration ist mit der zur. Synchronisation erforderlichen verzögerungslosen Beendigung eines Blocks vereinbar. $t_{1 / 2}$ wurde daher in verschiedenen Zellsystemen und im peripheren Blut nach ein- und mehrmaligen Puls-Dosen von HU bestimmt. Der größte Teil dieser Messungen wurde an Ratten der Stämme Marshall und BD IX durchgeführt, jedoch wurden wegen der Möglichkeit einer späteren Anwendung auch andere Säugerspecies zum Vergleich herangezogen. In den Abb. 8, 10 u. 12 sowie in Tab. 2 sind einige der gemessenen HU-Abfall-Kinetiken, bzw. die entsprechenden Werte für $t_{1 / 2}$ wiedergegeben.

Die Meßergebnisse zeigen zunächst, daß $t_{1 / 2}$ in den gemessenen Systemen mit der verwendeten HU-Nachweismethode exakt bestimmt werden kann und in einer Größenordnung liegt, welche der Forderung nach einer verzögerungslosen Beendigung eines DNA-Syntheseblocks in den meisten Fällen genügen sollte. So wird der Konzentrationsbereich zwischen $10^{-4} \mathrm{~m}$ und $10^{-5} \mathrm{~m}$ im Blut der Ratte in 1,5 Std durchlaufen (s. Abb. 8 u. 12), einer Zeit, die im Vergleich zu den bekannten $t_{C}$-Werten von Säugerzellen sehr kurz ist. $t_{1 / 2}$ zeigt bei verschiedenen Species charakteristische Unterschiede (Fabricius $u$. Rajewsky, 1971). Die $t_{1 / 2}$-Werte im Blut von Maus, Ratte und Mensch verhalten sich wie 1:1,7:7,6. Dagegen weichen die bei einer gegebenen Species (Marshall-Ratte) gemessenen $t_{1 / 2}$-Werte für Blut und Tumorgewebe (BICR-M1R-Tumor) nur um etwa $\pm 12 \%$ von einem gemeinsamen Mittelwert ab, so daß hier die im Blut gemessenen Konzentrationswerte auch für das Tumorgewebe als repräsentativ angesehen werden können.

Beim in vivo-Abbau von HU scheint der Leber eine zentrale Rolle zuzukommen. Dies wird aus den Ergebnissen von Experimenten deutlich, in denen der in vitro-Abbau von $\mathrm{HU}$ durch Leberhomogenat (Marshall-Ratte) bei $37^{\circ} \mathrm{C}$ mit Hilfe der HU-Nachweisreaktion verfolgt wurde (Fabricius u. Rajewsky, 1971). Der Abbau erfolgt hier mit einer $t_{1 / 2}$ von $30 \mathrm{~min}$ und liegt damit in der gleichen Größenordnung wie die entsprechenden unter in vivo-Bedingungen in Blut und Tumorgewebe gemessenen Werte (s. Tab. 2). Es war daher zu erwarten, daß nach 2/3-Hepatektomie eine Verlängerung der Halbwertszeiten auftreten würde. In der Tat ergab sich unter diesen Bedingungen für Blut und Tumorgewebe eine Erhöhung von $t_{1 / 2}$ um den Faktor 2,8 bzw. 2,5 (s. Tab. 2). In der intakten Leber der Ratte gelingt ein Nachweis von HU bereits 1 Std nach einer Dosis von $0,5 \mathrm{mg}$ $\mathrm{HU} / \mathrm{g}$ Körpergewicht nicht mehr, in der Restleber 2/3-hepatektomierter Tiere ist nach der gleichen Dosis HU nach 3 Std nicht mehr nachweisbar (s. Tab. 2).

Eine Ausnahme bildet der für den Embryo der BD IX-Ratte am 18. Tag der Gravidität gemessene Wert für $t_{1 / 2}$. Legt man die für den BICR-MIR-Tumor der Marshall-Ratte ermittelte Halbwertszeit zugrunde, so liegt der entsprechende Wert für den Embryo um einen Faktor 1,6 höher. Möglicherweise bietet der komplizierte Stoffaustausch zwischen maternem Kreislaufsystem und Foet eine Erklärung für diesen Befund. 
Tabelle 2. Halbwertszeit ( $\left.t_{1 / 2}\right)$ der HU-Konzentration in verschiedenen Geweben und Blut nach in vivo-Applikation von $\mathrm{HU}$

\begin{tabular}{|c|c|c|c|}
\hline Spezies (Stamm) & Gewebe/Blut & $\begin{array}{l}\text { HU-Dosis } \\
\text { (mg/g Körpergewicht) }\end{array}$ & $t_{1 / 2}(\min )$ \\
\hline Ratte (Marshall; 우) & BICR/MlR-Tumor & 0,25 & 29 \\
\hline Ratte (Marshall; ㅇ) & BICR/M1R-Tumor & 0,50 & 28 \\
\hline Ratte (Marshall; of) & BICR/M1R-Tumor & $2 \times 0,50^{2}$ & 29 \\
\hline $\begin{array}{l}\text { Ratte (Marshall; } 9 ; 3 \text { Std nach } \\
2 / a \text { Hepatektomie) }\end{array}$ & BICR/M1R-Tumor & 0,50 & 72 \\
\hline Ratte (Marshall; 우) & Leber & 0,50 & b \\
\hline $\begin{array}{l}\text { Ratte (Marshall; } q ; 3 \text { Std nach } \\
2 / 3 \text { Hepatektomie) }\end{array}$ & Leber & 0,50 & c \\
\hline $\begin{array}{l}\text { Ratte (BD IX; Embryo am } \\
\text { 18. Tag der Gravidität) }\end{array}$ & Embryo & 0,25 & 45 \\
\hline Maus (Balb/c; $\not)$ & Blut & 0,25 & 13 \\
\hline Ratte (Marshall; ㅇ) & Blut & 0,25 & 21 \\
\hline Ratte (Marshall; †) & Blut & 0,50 & 25 \\
\hline Ratte (Marshall; ㅇ) & Blut & $2 \times 0,50^{2}$ & 23 \\
\hline $\begin{array}{l}\text { Ratte (BD IX; ; ; 18. Tag } \\
\text { der Gravidität) }\end{array}$ & Blut & 0,25 & 20 \\
\hline $\begin{array}{l}\text { Ratte (Marshall; } 9 ; 3 \text { Std nach } \\
2 / 3 \text { Hepatektomie) }\end{array}$ & Blut & 0,50 & 61 \\
\hline Mensch $(\text { o })^{d}$ & Blut & $0,10^{\mathrm{m}}$ & 100 \\
\hline
\end{tabular}

- Im Abstand von 5 Std.

b Nicht meßbar, da HU bereits 1 Std nach HU-Puls nicht mohr nachweisbar.

- Nicht gemessen, da HU nur bis zu 2 Std nach HU-Puls nachweisbar.

d Untersuchung in Zusammenarbeit mit der Medizinisehen Klinik d. Universität Tübin. gen (Arbeitsgruppe Prof. Dr. W. Wilmanns).

- Oral; in Form des Präparats Litalir(H (Hydroxyharnstoff Squibb), v. Heyden AG, München.

Es war nunmehr die Abhängigkeit der Inhibition der DNA-Synthese und der Blockdauer von der initialen HU-Konzentration und ihrer Abfall-Kinetik zu analysieren. Die Abb. 8, 9 u. 10 zeigen Ergebnisse entsprechender Experimente. Nach einem HU-Puls von $0,5 \mathrm{mg} \mathrm{HU/g} \mathrm{Körpergewicht} \mathrm{sinkt,} \mathrm{wie} \mathrm{in} \mathrm{Abb.} 8$ aufgrund autoradiographischer Messungen dargestellt, der Anteil DNA-synthetisierender Zellen des BICR-MIR-Tumors scharf ab und beginnt nach Unterschreiten einer HU.Konzentration von etwa $2 \times 10^{-5} \mathrm{Mol} / 10^{3} \mathrm{~g}$, d. h. nach etwa 5 Std, wieder anzusteigen. Ebenso wie sein Beginn erfolgt auch die Beendigung des Blocks zeitlich scharf definiert. Die gleiche Abbildung zeigt, daß die Blockdauer durch einen nach einem Zeitintervall von 5 Std gegebenen zweiten HU.Puls $(0,5 \mathrm{mg} / \mathrm{g}$ Körpergewicht) auf etwa 10 Std verlängert werden kann. Auch hier ist die Beendigung des Blocks mit dem Unterschreiten der gleichen HU-Konzentration im Tumorgewebe $\left(\sim 2 \times 10^{-5} \mathrm{Mol} / 10^{3} \mathrm{~g}\right)$ korreliert.

Für die foetale Ratte (Abb. 9) beträgt die Blockdauer nach Injektion von $0,5 \mathrm{bzw}, 0,25 \mathrm{mg}$ HU/g Körpergewicht bei graviden BD IX.Ratten ebenfalls etwa 5 bzw. 2,5 Std, jedoch ist hier der Zeitpunkt der Beendigung des Blocks mit dem Unterschreiten einer HU-Konzentration von etwa $2 \times 10^{-4} \mathrm{Mol} / 10^{3} \mathrm{~g}$ Foetalgewebe 
(HU-Konzentration im Blut des Muttertieres zum gleichen Zeitpunkt etwa $2 \times 10^{-5} \mathrm{~m}$ !) korreliert (Abb. 10).

Da eine autoradiographische Auswertung allein aus methodischen Gründen keine quantitative Aussage bezüglich der während eines DNA-Syntheseblocks noch bestehenden Restsynthese gestattet, wurden beim Rattenembryo nach

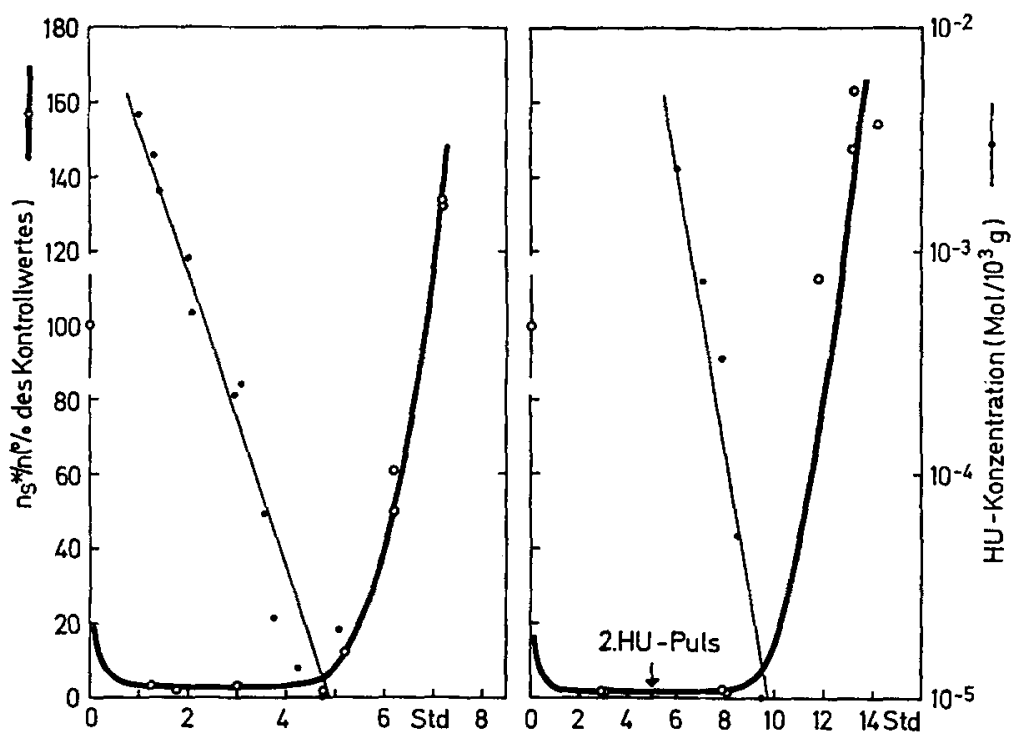

Abb. 8. Anteil DNA-synthetisierender Zellen $\left(\mathrm{n}^{*}{ }_{s} / \mathrm{n}\right)$ des BICR/MIR-Tumors der MarshallRatte als Funktion der Zeit nach einmaliger Injektion von $0,5 \mathrm{mg} \mathrm{HU/g} \mathrm{Körpergewicht}$ (linke Grafik), und nach zweimaliger Injektion von $0,5 \mathrm{mg} \mathrm{HU} / \mathrm{g}$ Körpergewicht im Abstand von 5 Std (rechte Grafik). Zusätzlich ist die HU-Konzentration im Tumorgewebe als Funktion der Zeit angegeben. Jeder Meßpunkt entspricht dem Mittelwert für einen Tumor; der Kontrollwert ( \pm Standardabweichung) ist ein Mittelwert für 8 Tumoren. Ordinaten, links: $\mathbf{n}_{s}{ }^{*} / \mathbf{n}$ (\% des Kontrollwertes), - $\%$-, rechts: HU-Konzentration (Mol/103 $\mathrm{g}),-0-$ Abszissen, linke Grafik: Zeit nach HU-Puls (Std), rechte Grafik: Zeit nach dem ersten HU.Puls (Std)

gründlicher Extraktion der säurelöslichen Fraktion Direktmessungen der eingebauten ${ }^{3} \mathrm{H}$-Aktivität im Flüssigkeitsszintillations-Spektrometer durchgeführt. Es ergaben sich $1 \mathrm{Std}$ nach Injektion von 0,25 bzw. 0,5 mg HU/g Körpergewicht bei jeweils 8 unabhängigen Bestimmungen Mittelwerte von $1,8 \%$ bzw. $0,9 \%$ der ${ }^{3} \mathrm{H}$-Aktivität der Kontrollwerte. Durch Langzeitexposition der entsprechenden Autoradiogramme konnte ferner gezeigt werden, $\mathrm{da} \beta$ die Restsynthese offenbar nicht einzelnen, gegenüber der inhibitorischen Wirkung des HU resistenten Zellen, sondern allen S-Zellen zuzuschreiben ist.

Es war weiter zu prüfen, ob die Hemmwirkung bei einer bestimmten, nach HU-Puls im Blut gemessenen HU-Konzentration derjenigen eines in vitroAnsatzes mit gleicher HU-Konzentration entspricht. Durch Vergleichsmessungen an HeLa-Zellen in Monolayerkultur konnte gezeigt werden, daß dies in der Tat der Fall ist: Bei Inkubation der Referenzzellen mit Blutplasmaproben, die zu ver- 
schiedenen Zeiten nach in vivo-Applikation von HU gewonnen worden waren, entsprach die Abhängigkeit der ${ }^{3} \mathrm{H}$-Thymidin-Einbauhemmung von der HUKonzentration derjenigen von Kulturen, denen entsprechende HU-Mengen im Kulturmedium zugesetzt worden waren (Abb. 11). Dieser Befund war insofern

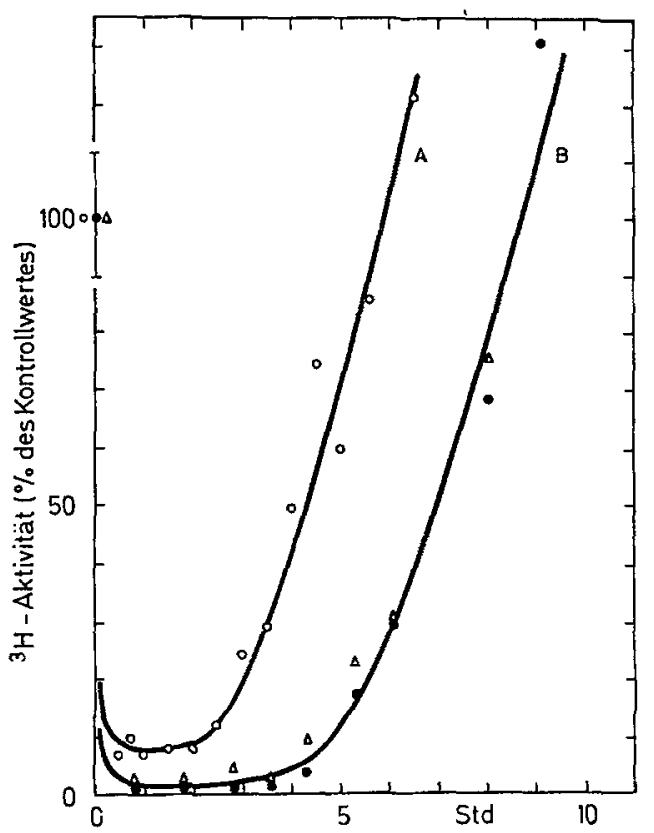

Abb. 9

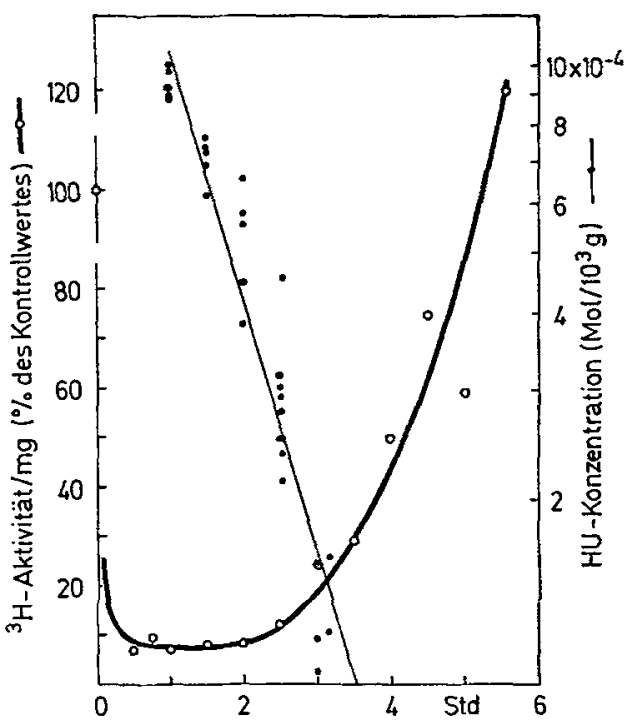

Abb. 10

Abb. 9. DNA-Synthese der fetalen Ratte als Funktion der Zeit nach Injektion von $0,25 \mathrm{mg}$ HU/g Körpergewicht (O, Kurve A) bzw. 0,5 mg HU/g Körpergewicht $(\triangle$, $\odot$, Kurve B) bei BD IX.Ratten am 18. Tag der Gravidität. Jeder MeBpunkt entspricht einem Mittelwert für 2-8 Embryonen. Kontrollwert \pm Standardabweichung. Ordinate: ${ }^{2} \mathrm{H}-A k$ tivität/mg Trockengewicht (\% des Kontrollwertes) $(0,0)$; bzw. ${ }^{3} \mathrm{H}$-Aktivität/ $10 \mu$ Mikrotomschnitt (\% des Kontrollwortes) ( $\triangle$ ) Abszisse: Zeit nach HU.Puls (Std)

Abb. 10. DNA.Synthese der fetalen Ratte als Funktion der Zeit nach Injektion von $0,25 \mathrm{mg} \mathrm{HU} / \mathrm{g}$ Körpergewicht bei BD IX-Ratten am 18. Tag der Gravidität. Zusä.tzlich ist die HU-Konzentration im Embryo als Funktion der Zeit angegeben. Die mit (O) bezeichneten Meßpunkte sind Mittelwerte für 3-8 Embryonen, die mit (๑) bezeichneten Meßpunkte entsprechen jeweils einem Embryo. Ordinaten, links: ${ }^{3} \mathrm{H}$-Aktivität/mg Trockengewicht $1 \%$ des Kontrollwertes), -O-, rechts: HU-Konzentration $\left(\mathrm{Mol} / 10^{3} \mathrm{~g}\right),-1-$ Abszisse: Zeit nach HU-Puls (Std)

von Bedeutung, als in Anbetracht des noch ungeklärten Mechanismus der DNASynthesehemmung durch HU nicht von vornherein unterstellt werden durfte, daß die gemessenen HU-Konzentrationskinetiken mit denjenigen des eigentlichen Inhibitors (falls es sich um ein Derivat von $\mathrm{HU}$ handeln sollte) parallel verlaufen würden.

Als Modellsystem für die Analyse der Kurz- und Langzeiteffekte einer temporären Blockade der DNA-Synthese auf die Kinetik proliferierender Zellpopula- 


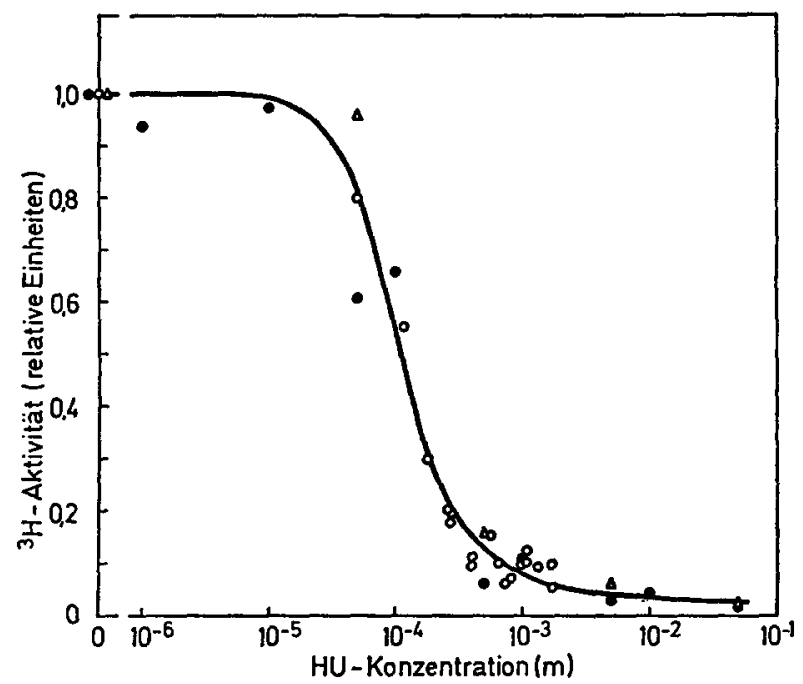

Abb. 11. Inhibition der DNA- Synthese in Hela-Zellen in Abhängigkeit von der HU-Konzentration des Kulturmediums. Messungen unter Standardbedingungen. Meßpunkte: Mittelwerte für $\geqq 3$ Bestimmungen, : Kulturmedium + HU, $\triangle$ : Humanblutplasma + HU, 0 : Humanblutplasma nach in vivo-Applikation von HU (kolorimetrische Bestimmung der HU-Plasmakonzentration). Ordinate: ${ }^{3} \mathrm{H}$-Thymidineinbau/Standardzellzahl (relative Einh.). Abszisse: HU-Konzentration des Kulturmediums bzw. Humanblutplasmas (m)
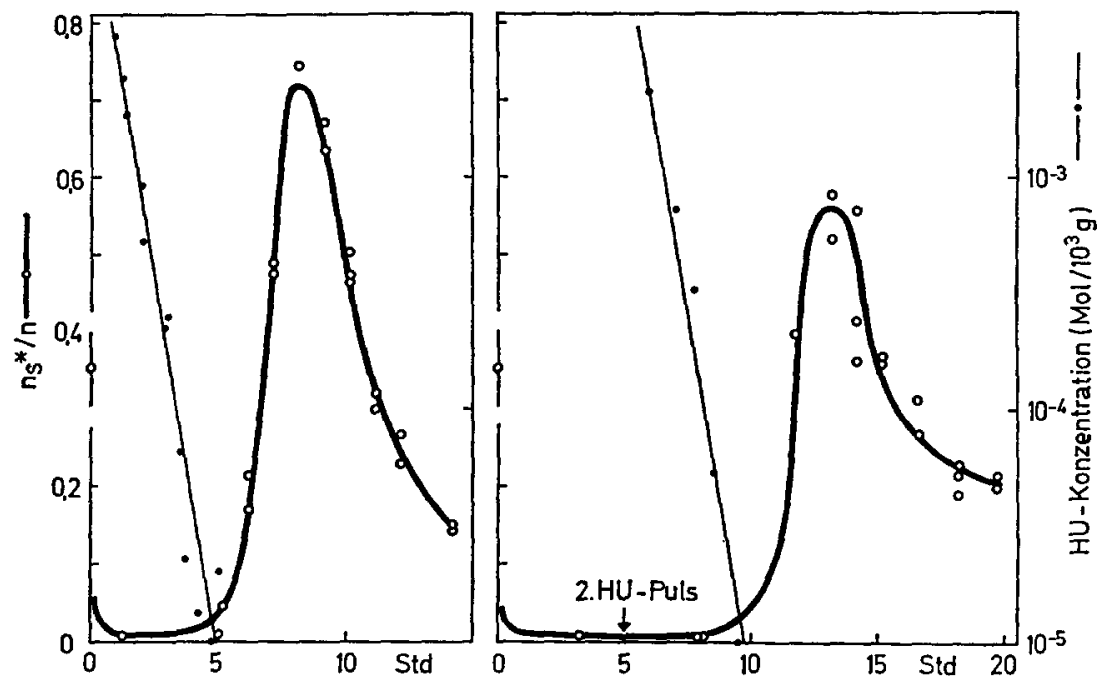

Abb. 12. Anteil DNA-synthetisierender Zellen $\left(n_{s} * / n\right)$ des BICR/M1R-Tumors der MarshallRatte als Funktion der Zeit nach einmaliger Injektion von $0,5 \mathrm{mg} \mathrm{HU} / \mathrm{g}$ Körpergewicht (linke Grafik), und nach zweimaliger Injektion von 0,5 mg HU/g Körpergewicht im Abstand von 5 Std (rechte Grafik). Zusätzlich ist die HU-Konzentration im Tumor als Funktion der Zeit angegeben. Jeder Meßpunkt entspricht dem Mittelwert für einen Tumor. Der Kontrollwert ( \pm Standardweichung) ist ein Mittelwert für 8 Tumoren. Ordinaten, links: $n_{s} * / n,-0-$, rechts: HU-Konzentration $\left(\mathrm{Mol} / 10^{3} \mathrm{~g}\right),-1-$ Abszissen: linke Grafik: Zeit nach HU-Puls (Std), rechte Grafik: Zeit nach dem ersten HU.Puls (Std) 
tionen in vivo wurde der BICR-MIR-Tumor der Marshall-Ratte verwendet. Das BICR-M1R-System erschien für diese Untersuchungen besonders geeignet, da seine Zellcyclusparameter zuvor bestimmt worden waren (s. Tab. 1). Bei den zellkinetischen Messungen wurde der Anteil DNA-synthetisierender Zellen $\left(\mathrm{n}_{s}{ }^{*} / \mathrm{n}\right)$, bzw. der Anteil von Zellen in Mitose $\left(n_{M} / n\right)$ als Funktion der Zeit nach Blockade der DNA-Synthese bestimmt.

In Abb. 12 ist die Kurzzeitkinetik des BICR/M1R-Systems nach Inhibition der DNA-Synthese für 5 Std bzw. 10 Std dargestellt. Der scharfe Anstieg von $n_{S} * / n$ nach Beendigung des Blocks und das Durchlaufen eines Peaks etwa 3 Std nach Beendigung des Blocks zeigt, daß eine partielle Synchronisation der Population erreicht wurde. Die Peaks für $n_{S}{ }^{*} / n$ werden in beiden Fällen etwa 4 Std später von Peaks für $\mathrm{n}_{M} / \mathrm{n}$ gefolgt (in Abb. 12 nicht dargestellt), die den Kontrollwert für $\mathrm{n}_{M} / \mathrm{n}$ um etwa einen Faktor 3,5 bzw. 2,5 übersteigen (Rajewsky, 1970(1); (s. auch Abb. 13). Während der Peakwert für $n_{S} * / n$ nach einem 5 Std-Block gut mit dem aufgrund der Zellaltersverteilung der asynchronen Population berechneten theoretischen Wert übereinstimmt, ist der Peakwert für $n_{S} * / n$ nach einem 10 StdBlock deutlich niedriger als der theoretisch erwartete Wert. Dies muß dahingehend interpretiert werden, daß während des Blocks ein Teil der blockierten S-Zellen inaktiviert wurde, und zwar wahrscheinlich infolge einer für dieses Zellsystem zu extensiven Blockadedauer ("unbalanced growth"; Cole u. Strauss, 1970; Eidinoff u. Rich, 1959; Kim u. Mitarb., 1967; Rueckert u. Mueller, 1960). In Anbetracht
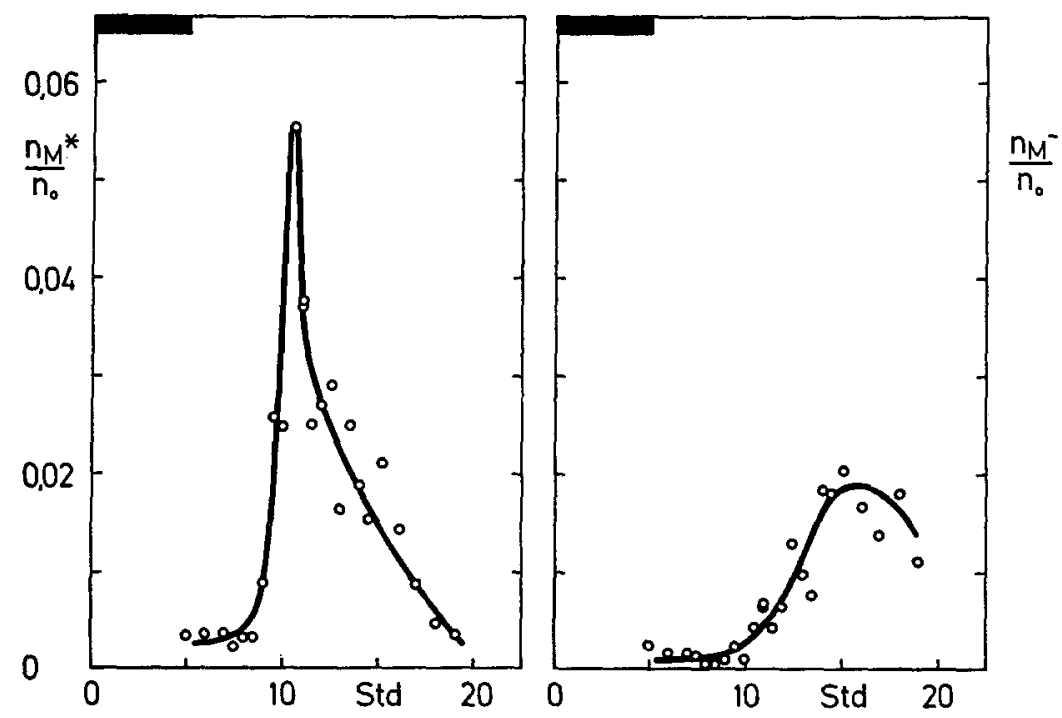

Abb. 13. Anteil von BICR/MIR-Zellen in Mitose als Funktion der Zeit nach Injektion von $0,5 \mathrm{mg} \mathrm{HU} / \mathrm{g}$ Körpergewicht. $30 \mathrm{~min}$ vor dem HU.Puls wurden die zu diesem Zeitpunkt in der S-Periode des Zellcyclus befindlichen Zellen mit ${ }^{3} \mathrm{H}$-Thymidin markiert. Die MeBwerte sind Mittelwerte für je 2 Tumoren. Die schwarzen Balken in den linken oberen Ecken der Grafiken geben die Dauer des DNA-Syntheseblocks an. Die Gesamtzahl der Zellen (n) wurde jeweils auf die Ausgangszellzahl $\left(\mathrm{n}_{0}\right)$ der Population vor der Mitose korrigiert. Linke Grafik: Anteil markierter BICR/MIR-Zellen in Mitose $\left(\mathrm{n}_{\mathbf{A}^{*}} / \mathrm{n}_{\mathbf{0}}\right)$; linke Ordinate. Rechte Grafik: Anteil unmarkierter BICR/M1R-Zellen in Mitose $\left(\mathrm{n}_{M-} / \mathrm{n}_{0}\right)$; rechte Ordinate. Abszissen: Zeit nach HU.Puls (Std) 
der zur Verlängerung der Blockadedauer verwendeten Technik (2 Pulsinjektionen von je 0,5 mg HU/g Körpergewicht im Abstand von $5 \mathrm{Std}$ ) könnte ein cytotoxischer Effekt jedoch auch darauf zurückzuführen sein, daß die blockierten Zellen ein weiteres $\mathrm{Mal}$ der hohen HU-Ausgangskonzentration von etwa $5 \times 10^{-3} \mathrm{Mol} /$ $10^{-3} \mathrm{~g}$ ausgesetzt wurden. Andererseits zeigt aber das Auftreten eines Mitosepeaks 4-5 Std nach dem Peak für $\mathrm{n}_{S}{ }^{*} / \mathrm{n}$, daß auch bei einer Blockdauer von 10 Std ein Teil der blockierten S-Zellen hinsichtlich ihrer Fähigkeit zur DNA-Synthese und Mitose intakt geblieben sein muß.

Obwohl im Falle des 5 Std-Blocks bereits die Höhe des erreichten Peaks für $\mathrm{n}_{S^{*}} / \mathrm{n}$ eine akute Inaktivierung von S-Zellen unwahrscheinlich macht, wurde zusätzlich die Passage der zuvor in $\mathrm{S}$ geblockten Zellen durch die erste auf den Block folgende Mitose verfolgt. Dazu wurden die S-Zellen der asynchronen BICR/ MlR-Population 30 min vor Beginn eines 5 Std-Blocks mit ${ }^{3} \mathrm{H}$-Thymidin vormarkiert, und nach Beendigung des Blocks die Passage markierter und unmarkierter Zellen durch die Mitose registriert. Die Abb. 13 zeigt das Ergebnis eines solchen Versuchs. Man erkennt deutlich, daß zunächst ausschließlich markierte Zellen $\left(\mathrm{n}_{M}{ }^{*} / \mathrm{n}_{0}\right)$ die Mitose durchlaufen (Maximum etwa 6 Std nach Beendigung des Blocks). Erst etwa 10 Std nach Beendigung des Blocks findet sich ein Maximum für den Mitoseindex unmarkierter Zellen $\left(\mathrm{n}_{M^{-}} / \mathrm{n}_{0}\right)$, welches den während des Blocks im $\mathrm{G}_{1}$-S-C̈bergangsbereich aufgelaufenen Zellen zuzuschreiben ist.

In Abb. 14 ist die Langzeitkinetik des BICR/M1R-Systems nach einer Blockdauer von $10 \mathrm{Std}$ dargestellt. Zusätzlich zu dem in Abb. 12 gezeigten ersten Peak für $n_{S} * / n$ bei etwa 13 Std tritt hier ein zweiter Peak bei etwa 26 Std (s. auch Abb. 15) auf, welcher dem Anteil der nach dem Block intakt gebliebenen S-Zellen zugeschrieben werden muß. Diese Zellen haben etwa 7-8 Std nach Beendigung des Blocks die Mitose passiert und durchlaufen nun nach einer $G_{1}$-Periode von normaler Dauer ihre nächste S.Periode. Der dritte, größere Peak, dessen Anstieg bei etwa 31 Std beginnt, wird durch die während des Blocks im $\mathrm{G}_{1}-\mathrm{S}$-Übergangsbereich akkumulierten Zellen verursacht.

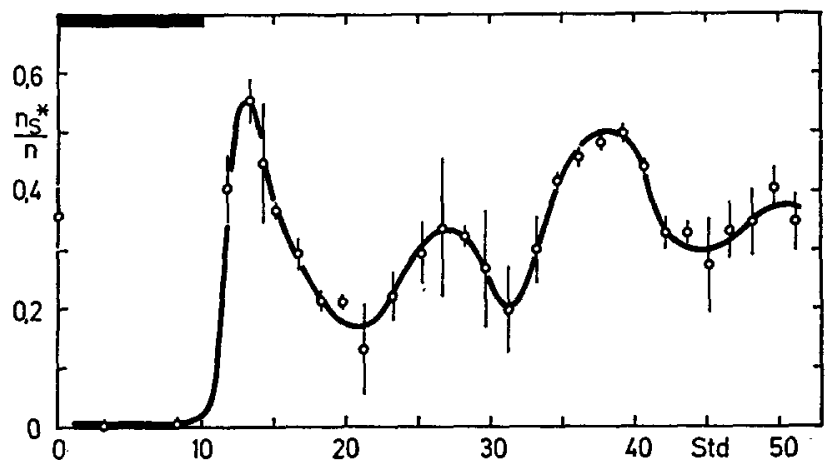

Abb. 14. Anteil DNA-synthetisierender BICR/MlR-Zellen $\left(n_{s}^{*} / n\right)$ als Funktion der Zeit nach zweimaliger Injektion von $0,5 \mathrm{mg} \mathrm{HU} / \mathrm{g}$ Körpergewicht im Abstand von $5 \mathrm{Std}$. Die Meßpunkte entsprechen Mittelwerten für 2-3 Tumoren. Die jeweiligen Standardabweichungen sind angegeben. Der schwarze Balken in der linken oberen Ecke der Grafik gibt die Dauer des DNA-Syntheseblocks an. Ordinate: $\mathrm{n}_{s}^{*} / \mathrm{n}$. Abszisse: Zeit nach dem ersten HU.Puls (Std). (Nach Rajewsky [1970 (1)] mit Genehmigung von Academic Press Inc., New York-London) 
Abb. 15 zeigt das Ergebnis eines Experiments, in dem beim BICR/MIRTumor nach einem initialen Block von 5 Std nach 30 Std, also zu Beginn des in Abb. 14 gezeigten dritten Peaks für $n_{S^{*}} / n$, eine zweite Blockade $(0,4 \mathrm{mg} \mathrm{HU} / \mathrm{g}$ Körpergewicht) durchgeführt wurde. Dieser zweite Block hat einen neuen ,,Initialpeak" mit einer gegenüber dem normalerweise nach einem 5 Std-Block auftretenden ersten Peak gesteigerten Höhe und Amplitude zur Folge. Daraus kann geschlossen werden, daß der Synchroniegrad durch ein an den Zellcyclusparametern orientiertes "timing" mehrfacher Blocks gesteigert werden kann.

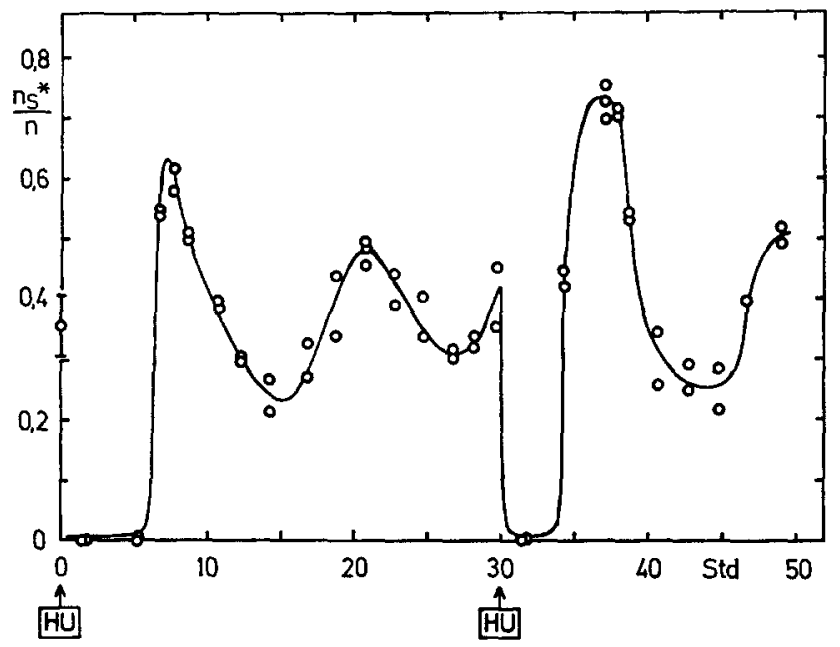

Abb. 15. Anteil DNA-synthetisierender BICR/MIR-Zellen $\left(n_{s}^{*} / n\right)$ als Funktion der Zeit nach Injektion von 0,5 und 0,4 mg HU/g Körpergewicht im Abstand von 30 Std. Jeder Meßpunkt entspricht dem Mittelwert für einen Tumor. Der Kontrollwert ( \pm Standardabweichung) ist ein Mittelwert für 8 Tumoren. Ordinate: $\mathrm{n}_{s} / \mathrm{n}$. Abszisse: Zeit nach dem ersten HU-Puls (Std). (Nach Rajewsky [1970 (1)] mit Genehmigung von Academic Press Inc., New YorkLondon)

In den Abb. 16, 17 u. 18 sind Ergebnisse proliferationskinetischer Messungen an der fetalen BD IX-Ratte (18. Tag der Gravidität) sowie an Milz und Leber der adulten Marshall-Ratte dargestellt. Dabei handelt es sich im Falle der fetalen Ratte um Messungen der ${ }^{3} \mathrm{H}$-Aktivität/mg Gewebe nach in vivo-Pulsmarkierung mit ${ }^{3} \mathrm{H}$-Thymidin, also nicht um die in allen anderen Fällen durchgeführte autoradiographische Bestimmung von $\mathbf{n}_{S} * / \mathbf{n}$.

Abb. 16 zeigt das Verhalten der DNA-Synthese bei fetalen Ratten nach Injektion einer Pulsdosis von $0,25 \mathrm{mg}$ HU/g Körpergewicht bei graviden BD IXRatten. In Analogie zu den Beobachtungen am BICR/MIR-Tumor führt dies zu einer etwa 2,5 Std dauernden Blockade der DNA-Synthese, die von einem raschen Anstieg, und nach Erreichen eines Peaks bei etwa 7-8 Std von einem erneuten Absinken gefolgt ist. Die Position eines offenbar vorhandenen zweiten Peaks kann wegen der Streuung der Meßwerte nicht sicher festgelegt werden. Die fetale Ratte enthält eine Kombination meist sehr rasch proliferierender Zellpopulationen. Bei 


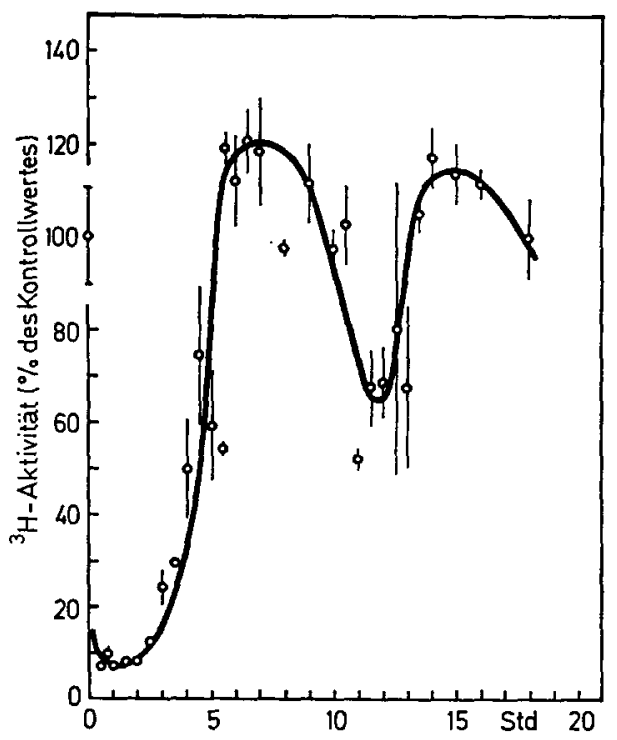

Abb. 16. DNA-Synthese der fetalen Ratte als Funktion der Zeit nach Injektion von 0,25 mg HU/g Körpergewicht bei BD IX-Ratten am 18. Tag der Gravidität. Die MeBpunkte ( \pm Standardabweichung) sind Mittelwerte für 3-8 Embryonen. Ordinate: ${ }^{3} \mathrm{H}$-Aktivität/mg Trockengewicht (\% des Kontrollwertes). Abszisse: Zeit nach HU-Puls (Std) - (Nach Rajewsky u.

Mitarb. (1971) mit Genehmigung von Academic Press Inc., New York-London)

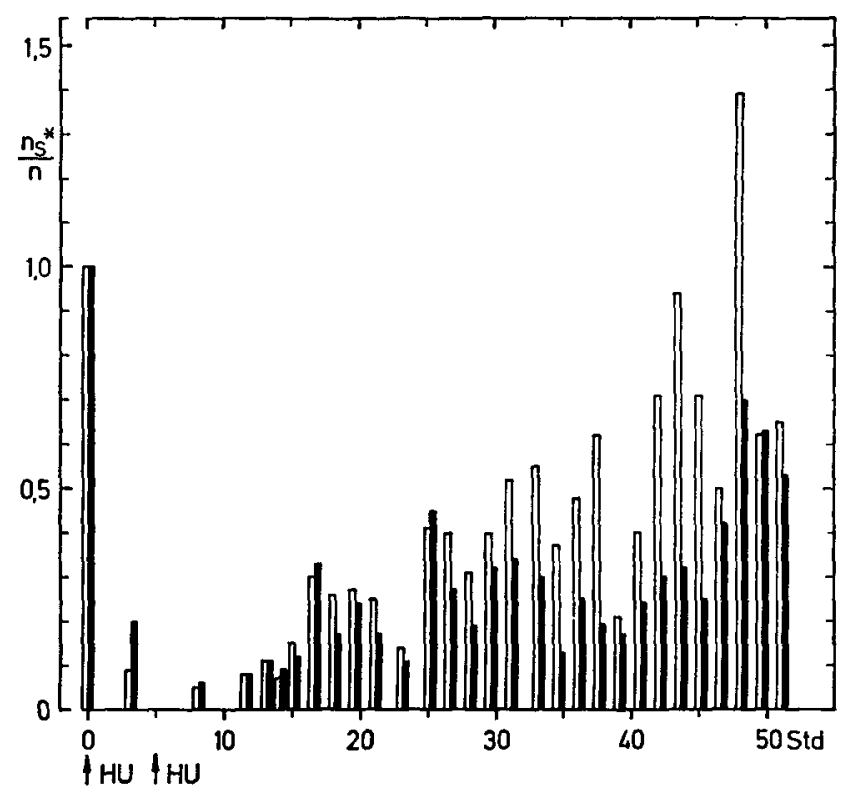

Abb. 17. Anteil DNA-synthetisierender Milzzellen $\left(n_{s}^{*} / \mathbf{n}\right)$ der adulten Marshall-Ratte (q) als Funktion der Zeit nach zweimaliger Injektion von $0,5 \mathrm{mg} \mathrm{HU} / \mathrm{g}$ Körpergewicht im Abstand von 5 Std. - Kleine Lymphocyten, $\square$ Alle Milzzellen. Die Kontrollwerte wurden auf den Wert 1,0 normiert. Ordinate: $\mathbf{n}_{s} * \mathbf{n}$ (relative Einheiten). Abszisse: Zeit nach dem ersten 
proliferierenden fetalen Zellsystemen ist der Anteil von $t_{S}$ an $t_{C}$ meist sehr hoch, d. h. $t_{G 1}$ und $t_{G 2}$ sind vergleichsweise von geringer Dauer (s. Pilgrim u. Mitarb., 1965). Daher kann als Folge der temporären Blockade der DNA-Synthese ein den Kontrollwert erheblich übersteigender Peakwert in diesem Falle nicht erwartet

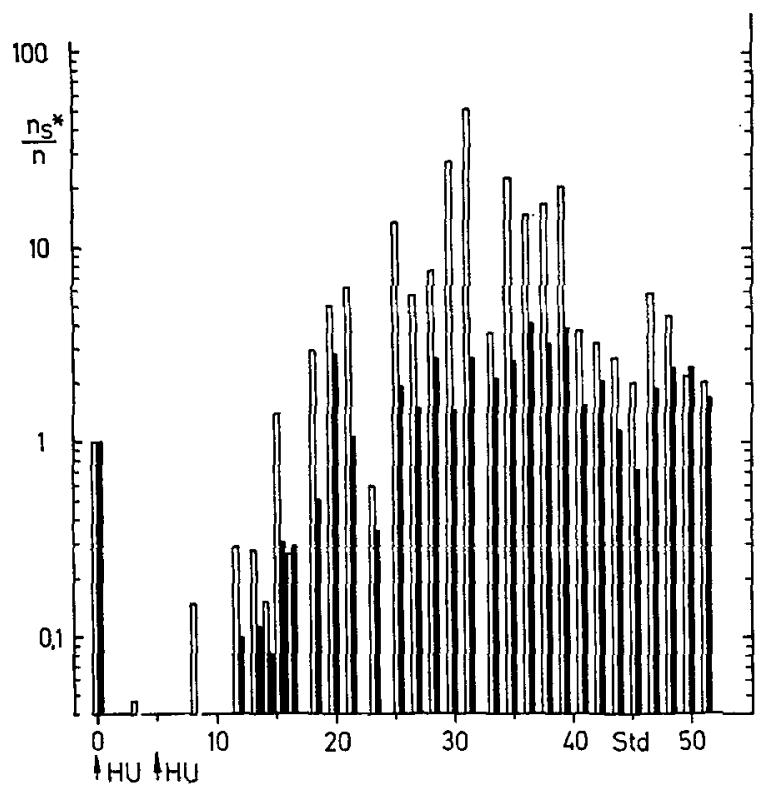

Abb. 18. Anteil DNA-synthetisierender Leberzellen $\left(n_{s}^{*} / n\right)$ der adulten Marshall-Ratte (q) als Funktion der Zeit nach zweimaliger Injektion von $0,5 \mathrm{mg} \mathrm{HU/g}$ Körpergewicht im Abstand von 5 Std. $\square$ Leberparenchymzellen, Nichtparenchymale Leberzellen. Die Kontrollwerte wurden auf den Wert 1,0 normiert. Ordinate: $\mathrm{n}_{\boldsymbol{s}^{*}} / \mathrm{n}$ (relative Einheiten). Abszisse: Zeit nach dem ersten HU-Puls (Std)

werden. Es besteht dementsprechend kein Grund zu der Annahme, daß eine höhergradige Inaktivierung von Zellen eingetreten ist. Dafür spricht auch die Beobachtung, daß Aufzuchtsrate und Lebenserwartung der Feten durch ein Blockexperiment des beschriebenen Typs nicht beeinflußt werden.

Die Proliferationskinetik der versehiedenen Zellpopulationen von Milz und Leber der adulten Ratte nach temporärer Blockade der DNA-Synthese läßt eine vom Verhalten des BICR-MIR-Tumors bzw. der embryonalen Ratte abweichende Reaktion dieser Zellsysteme erkennen.

In Abb. 17 ist das Verhalten von $n_{S} * / n$ in der Milz als Funktion der Zeit nach einem HU.Block durch zweimalige Injektion von $0,5 \mathrm{mg} \mathrm{HU} / \mathrm{g}$ Körpergewicht im Abstand von 5 Std dargestellt. Hier ergibt sich sowohl für die gesamten Zellen der Milz als auch für die kleinen Milzlymphocyten alleine ein stark verzögerter Wiederanstieg dieses Parameters. $\mathrm{Zu}$ einem Zeitpunkt von $50 \mathrm{Std}$ nach Blockbeginn hat $\mathbf{n}_{S} * / \mathbf{n}$ nur bei Bezug auf die Gesamtpopulation den Bereich des Kontrollwerts erreicht. Der im Vergleich zur Gesamtpopulation langsamere Anstieg von $\mathbf{n}_{S}{ }^{*} / \mathbf{n}$ für die Population der kleinen Lymphocyten weist auf eine hochgradige Schädigung besonders dieses Zelltyps hin. 
Die Parenchymzellpopulation der adulten Leber ist bekanntlich gekennzeichnet durch einen extrem niedrigen Anteil von Zellen in DNA-Synthese und Mitose, bzw. durch einen sehr hohen Anteil anscheinend nicht im Zellcyclus befindlicher (, $\mathrm{G}_{0}{ }^{4}{ }^{\prime}$ ) Zellen, welche die Fähigkeit besitzen, nach chemischer Schädigung oder teilweiser Entfernung der Leber wieder in den Zellcyclus einzutreten (Leberregeneration; s. Bucher, 1963). Der nach zweimaliger Injektion von 0,5 mg HU/g Körpergewicht im Abstand von $5 \mathrm{Std}$ für diese Zellpopulation beobachtete Anstieg von $\mathrm{n}_{S}{ }^{*} / \mathrm{n}$ auf etwa das 30-50fache des Kontrollwerts (s. Abb. 18) stellt ohne Zweifel eine „regenerative" Reaktion dar, d. h. sie wird im wesentlichen durch Stimulation zuvor nicht im Zellcyclus befindlicher Zellen verursacht. In Analogie zu der Situation nach partieller Hepatektomie beginnt $n_{S} * / n$ etwa 15 Std nach dem ersten HU-Puls über den Kontrollwert anzusteigen. Dies läßt vermuten, daß bereits dem ersten HU-Puls ein ,,toxischer“ Effekt auf die Parenchymzellpopulation zuzuschreiben ist. Im Gegensatz zur Parenchymzellpopulation steigt der $\mathbf{n}_{S} * \mathbf{n}$-Wert für die nicht-parenchymalen Zellen nur auf das maximal 2-4fache des Kontrollwertes an. Bei beiden Zellpopulationen beginnt der Wiederanstieg von $\mathbf{n}_{S} * / \mathbf{n}$, entsprechend den Verhältnissen beim BICR/M1R-Tumor und bei der fetalen Ratte, etwa 5 Std nach dem zweiten HU-Puls.

\section{Diskussion}

Das in den vorliegenden Experimenten zur in vivo-Synchronisation proliferierender Zellpopulationen verwendete Verfahren basiert auf der Vorstellung, daB eine temporäre spezifische Blockade der DNA-Synthese die in der S-Periode des Zellcyclus befindlichen Zellen daran hindert, ihre DNA-Synthese zuendezuführen, während die z. Z. des Blocks in $G_{2}$, M oder $G_{1}$ befindlichen Zellen ihren Weg durch den Zellcyclus ungehindert fortsetzen und sich schließlich im $\mathrm{G}_{1}$-S-Übergangsbereich aufstauen. Nach Beendigung des Blocks liegt dann eine teilsynchronisierte Zellpopulation vor. Die temporäre Blockade der DNA-Synthese führt dabei zu einer charakteristischen Veränderung des normalen Zellaltersverteilungsdiagramms der asynchronen Population (vgl. Abb. 6 u. 7). Der Grad der durch einen Block der DNA-Synthese erreichbaren Synchronie hängt ab von der Blockdauer, von der relativen Dauer von $t_{S}$ im Vergleich zu $t_{C}$ sowie von der Verteilung von $t_{C}$ bei der gegebenen Zellpopulation. Mit anderen Worten, um je weniger $\mathbf{t}_{C}$ die Dauer der S-Periode $\left(\mathrm{t}_{S}\right)$ übersteigt, je kürzer die Blockdauer im Vergleich zu $\mathrm{t}_{C}-\mathrm{t}_{S}$, und je größer die Streuung von $t_{C}$ (und der Dauer der einzelnen Zellcyclusperioden) (vgl. Abb. 2), desto geringer der Grad der erreichbaren Synchronie. Eine zusätzliche Verbesserung des Synchroniegrades kann grundsätzlich auf zwei Wegen erzielt werden:

a) Die blockierten Zellen können für die Dauer des Blocks nicht nur in S arretiert, sondern infolge cytotoxischer Effekte des Inhibitors auch abgetötet, $d . h$. aus der proliferativen Fraktion der Population eliminiert werden. Die synchronisierte Population besteht dann nur noch aus den im $\mathrm{G}_{1}-\mathrm{S}$-Übergangsbereich aufgestauten Zellen, d. h. ihre Zellaltersverteilung ist wesentlich enger und ihr Synchroniegrad damit entsprechend höher geworden. Dieser Effekt tritt bei der temporären Blockade der DNA-Synthese häufig in mehr oder weniger ausgeprägter Weise auf. Die gezielte Anwendung hoher Inhibitorkonzentrationen, bzw. excessi- 
ver Blockzeiten zur Ausschaltung der blockierten S-Zellen wird jedoch unter in vivo-Bedingungen naturgemäß auf spezielle Fälle beschränkt bleiben müssen.

b) Es können mehrfache Blocks nach einem an den Zellcyclusparametern der Population orientierten zeitlichen Schema angewendet werden. So wird ein zweiter Block, der zeitlich so angesetzt ist, daß er die aus dem ersten Block entlassenen S-Zellen im $\mathrm{G}_{1}-\mathrm{S}$-Übergangsbereich vor ihrer nächstfolgenden S-Periode abfängt, den Grad der Synchronie wesentlich erhöhen (vgl. Abb. 15).

Unsere Untersuchungen zeigen, daß eine in vivo-Synchronisation proliferierender Säugergewebe durch temporäre Inhibition der DNA-Synthese unter geeigneten Bedingungen erreicht werden kann. Dabei hat sich Hydroxyharnstoff (HU) wegen seiner hohen Spezifität und Wirksamkeit als besonders geeignet erwiesen. Die Substanz ist in den letzten Jahren mit unterschiedlichen Erfolgen auch in der Tumortherapie verwendet worden (Literatur s. Ariel, 1970). Sie bietet neben einer geringen allgemeinen Toxicität außerdem den für eine Anwendung zur Synchronisation entscheidenden Vorzug, da $B$ ihr Abbau im Säugerorganismus sehr rasch erfolgt, und damit eine nahezu verzögerungsfreie Beendigung von DNA-Syntheseblocks ermöglicht.

Der Mechanismus der DNA-Synthesehemmung durch HU ist noch nicht vollständig geklärt. Neben einer Inhibition des Ribonucleotid-Reduktase-Systems (Adams u. Lindsay, 1967; Gale, 1968; Krakoff u. Mitarb., 1968; Young u. Hodas, 1964; Young u. Mitarb., 1967(2)) werden auch direkte Wirkungen auf die DNA (Rosenkranz, 1970; Rosenkranz u. Jacobs, 1968; Rosenkranz u. Mitarb., 1968; Rosenkranz u. Mitarb., 1969) sowie die Entstehung aktiver Metabolite unter in vivo-Bedingungen (Rosenkranz, 1970; Rosenkranz u. Mitarb., 1969) diskutiert. HU wird in vivo in der Hauptsache zu Harnstoff abgebaut (Adamson u. Mitarb., 1965(1); Colvin u. Bono, 1970). Das für den Abbau der Substanz entscheidende Organ ist die Leber. Nach in vivo-Applikation von HU bestimmt die Abbaurate in der Leber die Abfallkinetik des Inhibitors in Blut und Geweben (Fabricius u. Rajewsky, 1971; vgl. Tab. 2). Mit Hilfe eines modifizierten Hydroxamatnachweises (s. Fabricius u. Rajewsky, 1971) kann die HU-Konzentration in Blut und Geweben exakt gemessen werden. Die HU-Konzentrationswerte für Blut und Tumorgewebe (BICR/MIR-Tumor) bei der Ratte unterscheiden sich nur unwesentlich. Dagegen läßt sich die für eine bestimmte Säugerspecies gemessene Halbwertszeit $\left(t_{1 / 2}\right)$ des HU-Abbaus nicht direkt auf andere Species übertragen. Während beispielsweise $t_{1 / 2}$ für das Blut der Maus etwa 13 min beträgt, liegen die entsprechenden Werte für die Ratte bzw. den Menschen um einen Faktor 1,7 bzw. 7,6 höher. In den untersuchten Geweben der Ratte stieg die nach Injektion von $0,25 \mathrm{bzw} .0,5 \mathrm{mg} \mathrm{HU} / \mathrm{g}$ Körpergewicht nahezu vollständig blockierte DNASynthese im allgemeinen nach Unterschreiten einer HU-Konzentration von etwa $2 \times 10^{-5} \mathrm{Mol} / 10^{3}$ wieder an. Dagegen trat bei der fetalen Ratte die Beendigung des Blocks bereits bei Unterschreiten einer HU.Konzentration von etwa $2 \times 10^{-4} \mathrm{Mol} / 10^{3} \mathrm{~g}$ ein. Ein ähnlicher Schwellenwert $\left(\sim 1,5 \times 10^{-4} \mathrm{Mol} / 10^{3} \mathrm{~g}\right)$ ergab sich für menschliche Leukämiezellen (Rajewsky $\mathbf{u}$. Grüneisen, in Vorbereitung).

Während der Synchronisationseffekt nach Blockdauern von $2,5 \mathrm{Std}$ bzw. 5 Std beim BICR/MIR-Tumor der Ratte, und mit großer Wahrscheinlichkeit auch bei 
der fetalen Ratte, den auf der Zellaltersverteilung basierenden theoretischen Erwartungen entsprach, traten nach einer Blockdauer von $10 \mathrm{Std}$ durch zweimalige Injektion von 0,5 mg HU/g Körpergewicht im Abstand von 5 Std Anzeichen für cytotoxische Effekte auf. Diese schienen beim BICR/MIR-Tumor auf einen Teil der blockierten S-Zellen beschränkt zu sein. Dagegen muß im Falle der Milz- und Leberparenchymzellen damit gerechnet werden, daß auch solche Zellen inaktiviert wurden, die sich während des Blocks nicht in der S-Periode des Zellcyclus befanden. Es konnte zwar für den Fall eines 5 Std-Blocks beim BICR-MIR-Tumor gezeigt werden, daß die in $\mathrm{S}$ blockierten Zellen nach Beendigung des Blocks die nächstfolgende Mitose offenbar intakt passieren; jedoch kann aus methodischen Gründen die Überlebenswahrscheinlichkeit bzw. Proliferationsfähigkeit dieser Zellen in vivo nicht über mehrere Cyclen hin verfolgt werden. Aussagen über die langfristige Uberlebenswahrscheinlichkeit von Zellen, deren DNA.Synthese in vivo temporär blockiert wurde, sind daher vorläufig nicht möglich.

Cytotoxische Wirkungen großer HU-Dosen auf Zellsysteme mit hohen Proliferationsraten (Kryptenepithelien des Dünndarms, Knochenmark, Thymus, Milz und Lymphknoten) sind von verschiedenen Autoren beschrieben worden (Farber u. Baserga, 1969; Philips u. Mitarb., 1967). Auch bei der nach unserer Methode durchgeführten Synchronisation der Kryptenepithelien im Dünndarm der Maus ist auf eine Inaktivierung von S-Zellen geschlossen worden (Gillette u. Mitarb., 1970). Auffällig ist die außerordentlich hohe Empfindlichkeit lymphatischer Zellen, die anscheinend bereits durch kurzzeitige HU-Blocks irreversibel geschädigt werden können (vgl. Abb. 17). Die damit gegebene Möglichkeit, eine Zellpopulation vom lymphatischen Typ durch eine temporäre Blockade der DNA-Synthese mit zusätzlicher Elimination der blockierten S-Zellen zu synchronisieren, ist kürzlich an Zellen eines transplantablen Mäuselymphoms der AKR/J-Maus ausgenutzt worden (Madoc-Jones u. Mauro, 1970; Mauro u. Madoc-Jones, 1969). Allerdings wurde hier nicht die proliferationskinetische Reaktion der Population nach Beendigung des Blocks analysiert, sondern eine bei diesem System mögliche Messung der Fähigkeit der Zellen zur Koloniebildung in der Milz durchgeführt. Eine proliferationskinetische Analyse wäre insofern notwendig gewesen, als Hinweise dafür vorliegen, daß die toxische Wirkung von $\mathrm{HU}$ bei lymphatischen Zellen nicht auf S-Zellen beschränkt sein muß. So sind cytotoxische Effekte von HU auch bei der ,ruhenden“ Population der kleinen Knochenmarkslymphocyten beobachtet worden (Bohne u. Mitarb., 1970). In diesem Zusammenhang ist die an der Parenchymzellpopulation der adulten Rattenleber nach einem 10 Std-Block beobachtete, ,regenerative" Reaktion von $\mathrm{n}_{S}{ }^{*} / \mathrm{n}$ (vgl. Abb. 18) von Interesse, die auch auf eine Schädigung nicht im Zellcyclus befindlicher, sog. „, $\mathrm{G}_{0}$ “-Zellen hinweist. Dagegen konnte bei den DNA-synthetisierenden Zellen der regenerierenden Leber (sowie anderer normalerweise ruhender Zellsysteme nach Stimulation der DNA-Synthese) eine Inaktivierung durch HU nicht nachgewiesen werden (Farber u. Baserga, 1969; Schwartz u. Mitarb., 1965).

Als „Index“ für den Grad der bezüglich des Durchlaufens der DNA-Synthese erreichten Synchronie kann die Differenz zwischen dem auf die Blockade folgenden Peak und dem anschließenden Minimum für $\mathrm{n}_{S} * \mathrm{n}$ verwendet werden (Sinclair, 1969). Für den BICR/MIR-Tumor der Ratte würde dieser Index nach einem 5 Std- 
Block bei $0,5-0,6$ liegen. Dieser Wert erscheint relativ niedrig, wenn man ihn mit in Zellkulturexperimenten gemessenen Indices von etwa 0,8 (Sinclair, 1969) vergleicht. Es ist jedoch zu berücksichtigen, daß Zellkulturen im allgemeinen eine weit geringere Streuung von $t_{c}$ aufweisen als sie für Zellpopulationen unter in vivoBedingungen meist gefunden wird (Steel u. Mitarb., 1966; Steel u. Hanes, 1971). Im übrigen wird der wirkliche Synchroniegrad immer dann höher sein als durch diesen Index angegeben, wenn die Anzahl der unmarkierten Zellen bei der Bestimmung von $n_{S}^{*} / \mathbf{n}$ S-Zellen einschließt, die während des Blocks abgetötet, aber aus dem entsprechenden Zellsystem noch nicht eliminiert wurden.

Die proliferationskinetischen Befunde am BICR/MIR-Tumor enthalten Hinweise dafür, daß Zellen, die in der S-Periode blockiert worden waren, nach Beendigung des Blocks die DNA-Synthese schneller durchlaufen als unter normalen Bedingungen. Ein derartiger Effekt würde zu einer zeitweisen Erhöhung der Mitoserate führen. Dadurch würden die Mitosepeaks verständlich, die etwa $7 \mathrm{Std}$ nach Beendigung der Blocks beobachtet werden und die aufgrund der Zellaltersverteilung zu diesem Zeitpunkt theoretisch zu erwartenden Werte für $\mathbf{n}_{M} / \mathrm{n}$ erheblich übersteigen. Der gleiche Effekt könnte auch für die Trennung zweier Subpopulationen [a) Zellen, die während des Blocks in S arretiert wurden; b) Zellen, die während des Blocks im $\mathrm{G}_{\mathbf{1}}$-S-Übergangsbereich angestaut wurden] verantwortlich sein, die sich im Auftreten zweier getrennter Peaks für $n_{s} * / n$ nach der ersten auf den Block folgenden Mitose ausdrückt (s. Abb. 14 u. 15). Eine Verkürzung von $t_{S}$ nach temporärer Hemmung der DNA-Synthese ist für einige Zellstämme in Kultur beschrieben worden (Pfeiffer u. Tolmach, 1967; Rueckert u. Mueller, 1960; Till u. Mitarb., 1963). Für die vermutete Beschleunigung der DNASynthese kann eine befriedigende Deutung derzeit nicht gegeben werden. Es ist unwahrscheinlich, daß die während des DNA-Syntheseblocks beobachtete Restsynthese, die wohl auf eine Nucleotidpool-Reserve der Zellen zurückzuführen ist, einen solchen Effekt hervorrufen kann. Da HU die RNA- und Proteinsynthese nicht wesentlich beeinflußt (Pollack u. Rosenkranz, 1967; Young u. Hodas, 1964) wäre es auch denkbar, daß während eines HU-Blocks eine Anreicherung von „Initiator-"Proteinen in den blockierten S-Zellen erfolgt, die nach Beendigung des Blocks eine ,synchronisierende“ Wirkung auf die zeitliche Sequenz der Replikon-Initiation in den Chromosomen (Prescott, 1969; Rajewsky, 1970 (1) bewirken und damit zu einer Verkürzung von $t_{S}$ führen könnte.

Die dargestellten Untersuchungen zur in vivo-Synchronisation normaler und maligner Säugerzellen sind im Hinblick auf Problemstellungen der experimentellen und klinischen Krebsforschung durchgeführt worden. So ist die Verfügbarkeit in vivo vorsynchronisierter Targetzellsysteme z. B. eine wichtige Voraussetzung für die Prüfung der Frage nach dem Vorhandensein Zellcyclusphasen-spezifischer Empfindlichkeitsmaxima für die Initiation der malignen Transformation durch cancerogene Agentien. Für derartige Untersuchungen bieten sich chemische Cancerogene an, die in vivo mit sehr kurzer Halbwertszeit abgebaut werden („Pulscancerogene“; Rajewsky, 1970 (2)), z. B. Verbindungen vom Typ des Äthylnitrosoharnstoffs (Druckrey u. Mitarb., 1967). Eine einzige Pulsdosis dieser Substanz, in einem bestimmten Stadium der Gravidität appliziert, erzeugt bei den Nachkommen gravider Ratten mit hoher Ausbeute maligne Tumoren (Druckrey u. Mitarb., 1967). Es war das Ziel der an fetalen BD IX-Ratten durch- 
geführten Synchronisationsversuche, eine Grundlage für die Bearbeitung der obengenannten Fragen zu schaffen.

Die Bedeutung synchronisierter Zellsysteme für die Prüfung der Zellcyclusphasen-Spezifität der cytociden Wirkung chemischer Substanzen oder ionisierender Strahlung braucht nicht besonders betont $\mathrm{zu}$ werden. Für eine ganze Reihe chemischer Verbindungen (Mauro u. Madoc-Jones, 1970) sowohl als auch für Röntgenstrahlung (Sinclair, 1968) ist eine solche, zum Teil außerordentliche starke Phasenspezifität an Zellkulturen bereits gezeigt worden. Entsprechende Verhältnisse scheinen auch bezüglich der Immuncytolyse bei bestimmten Zellstämmen in Kultur (Cikes, 1970; Shipley, 1971) und experimentellen Tumoren in vivo (Rajewsky u. Grüneisen, in Vorbereitung) vorzuliegen. Die Relevanz dieser Befunde für die proliferierenden Zellen maligner Tumoren muß an geeigneten in vivo-Systemen nachgeprüft werden.

Grundsätzlich kann daran gedacht werden, der therapeutischen Anwendung eines phasenspezifischen Agens eine (Teil-)Synchronisation der proliferierenden Tumorzellen vorzuschalten, um einen größeren Anteil maligner Zellen während ihres Empfindlichkeitsmaximums zu treffen. Jedoch müßten dazu gleichzeitig Verfahren ausgearbeitet werden, die es gestatten, die infolge ihrer Mitsynchronisation ebenfalls erhöhte Schädigungsgefahr für normale Zellsysteme des Organismus auf ein tolerables $\mathrm{Maß}$ zu reduzieren. Hierzu könnte unter anderem die Tatsache ausgenutzt werden, daß sich die Zellcyclusparameter der meisten Zellsysteme in spezifischer Weise unterscheiden. Als Funktion der Zeit nach Synchronisation würde daher auch die Lage der Empfindlichkeitsmaxima einer Tumorzellpopulation mit großer Wahrscheinlichkeit zunehmend von denen der Normalpopulation abweichen. Andererseits sollte die "regenerative Reserve" normaler Zellsysteme nicht unterschätzt werden. Eine wesentliche Schwierigkeit besteht zur Zeit noch darin, daß die Zellcyclusparameter vor der Therapie nur in den seltensten Fällen gemessen oder wenigstens abgeschätzt werden können. Ihre Kenntnis ist jedoch für eine effektive Synchronisation erforderlich. Inwieweit eine in vivo-Synchronisation tatsächlich als Teil eines an den Zellcyclusparametern der malignen Population orientierten Therapieschemas Verwendung finden kann, muß der weiteren Entwicklung auf diesem Gebiet überlassen bleiben. Uber zur Zeit im Gange befindliche Untersuchungen zu diesem Fragenkomplex wird zu gegebener Zeit berichtet werden.

$\mathrm{Zu}$ besonderem Dank verpflichtet sind die Autoren Herm Prof. Dr. H. Friedrich-Freksa für sein Interesse und die großzügige Unterstützung der Arbeit, Herrn Dr. G. G. Steel, Biophysics Department, Institute of Cancer Research, London, für die Computeranalyse der „Markierte-Mitosen"-Daten, sowie den Herren Dipl.-Biochem. J. Oberbarnscheidt, MaxPlanck-Institut für Virusforschung, Tübingen, Dr. F. S. Philips, Sloan-Kettering-Institute for Cancer Research, New York, Prof. Dr. Z. Simon, Institut f. Organische Chemie, Universität Timisoara, und Prof. Dr. W. Wilmanns, Medizinische Klinik der Universität Tübingen, für wertvolle Hinweise und Diskussionen. Die HU.Konzentrationsmessungen wurden von E. Fabricius im Rahmen einer Dissertation an der Universität Tübingen durchgeführt.

Miss B. Stearns, Squibb Institute for Medical Research, New Brunswick, N. J., danken wir für die freundliche therlassung einer Testmenge von HU.

Für ausgezeichnete technische Mitarbeit sind wir Frau I. Arndt, Frau O. Beck, Fräulein T. Müller und Frau H. Rajewsky verpflichtet.

Ein Teil der Untersuchungen wurde durch die Deutsche Forschungsgemeinschaft unterstuitzt. 


\section{Literatur}

Adams, R.L.P., Lindsay,J.G.: Hydroxyurea-reversal of inhibition and use as a cell-synchronizing agent. J. Biol. Chem., 242, 1314 (1967).

Adamson, R.H., Ague, S.L., Hess, S.M., Davidson,J.D.: (1) The distribution, excretion and metabolism of hydroxyurea-14 C. J. Pharmacol. Exptl. Therap., 150, 322 (1965).

- Yancey,S.T., Ben,M., Loo,T.L., Rall,D.P.: (2) Some aspects of the antitumor activity and pharmacology of hydroxyurea. Arch. Intern. Pharmacodyn. 153, 87 (1965).

Ariel, I.M.: Therapeutic effects of hydroxyurea. Cancer, 25, 705 (1970).

Barrett,J.C.: A mathematical model of the mitotic cycle and its application to the interpretation of percentage labeled mitoses data. J. Natl. Cancer Inst. 37, 443 (1966).

Bergmann,F., Segal,R.: The separation and determination of microquantities of lower aliphatic acids, including fluoroacetic acids. Biochem. J. 62, 542 (1956).

Bohne,F., Haas,R.J., Fliedner,T.M., Fache,I.: The role of slowly proliferating cells in rat bone marrow during regeneration following hydroxyurea. Brit. J. Haematol. 19, 533 (1970).

Bresciani,F.: A comparison of the cell generative cycle in normal, hyperplastic and neoplastic mammary gland of the $\mathrm{C3H}$ mouse. In: Cellular radiation biology. 18th Annual

Symposium on Fundamental Cancer Research, p. 547. The University of Texas M.D. Anderson Hospital and Tumor Institute. Baltimore: The Williams and Wilkins Company (1965).

Bucher,N.L.R.: Regeneration of mammalian liver. Intern. Rev. Cytol. 15, 245 (1963).

Bush, E.T.: General applicability of the channels ratio method of measuring liquid scintillation counting efficiencies. Analyt. Chem., 35, 1024 (1963).

Cikes,M.: Relationship between growth rate, cell volume, cell cycle kinetics, and antigenetic properties of cultured murine Lymphoma cells. J. Natl. Cancer Inst. 45, 979 (1970).

Cleaver,J.E.: Thymidine metabolism and cell kinetics. North Holland Research Monograph, Frontiers of Biology, Vol. 6, Herausgegeben von A. Neuberger und E. L. Tatum. North Holland Publishing Co., Amsterdam (1967).

Cole,M.B., Strauss, B.: Cell killing and the accumulation of breaks in the DNA of HEp-2 cells incubated in the presence of hydroxyurea. Cancer Res. 30, 2314 (1970).

Colvin,M., Bono, Jr., V.H.: The enzymatic reduction of hydroxyurea to urea by mouse liver. Cancer Res. 30, 1516 (1970).

Dresler, W.F.C., Stein, R.: Uber den Hydroxylharnstoff. Ann. Chim. 150, 242 (1869).

Druckrey,H.: Genotypes and phenotypes of ten inbred strains of BD-rats. ArzneimittelForsch. 21, 1274 (1971).

- Preussmann,R., Ivankovic,S., Schmähl,D.: Organotrope carcinogene Wirkung bei 65 verschiedenen N-Nitroso-Verbindungen an BD-Ratten. Z. Krebsforsch. 69, 103 (1967).

Eidinoff,M.L., Rich,M.A. Growth inhibition of a human tumor cell strain by 5-fluoro-2'deoxyuridine: Time parameters for subsequent reversal by thymidine. Cancer Res. 19, 521 (1959).

Fabricius, E., Rajewsky, M.F.: Determination of hydroxyurea in mammalian tissues and blood. Europ. J. Clin. Biol. Res. 16, 679 (1971).

Farber,E., Baserga, R.: Differential effects of hydroxyurea on survival of proliferating cells. Cancer Res. 29, 136 (1969).

Gale,G.R.: Antagonism by deoxyribosides of the inhibitory action of certain hydroxamic acids on deoxyribonucleic acid synthesis. Experientia 24, 57 (1968).

Gillette, E.L., Withers, H.R., Tannock, I.F.: The age sensitivity of epithelial cells of mouse small intestine. Radiology 96, 639 (1970).

Higgins, G.M., Anderson, R.M.: Experimental pathology of the liver. I. Restoration of the liver of the white rat following partial surgical removal. Arch. Path. 12, 186 (1931).

Jacobs, S.J.: Studies on the mode of action of hydroxyurea. Ph. D. Dissertation, Columbia University (1968).

Kalberer,F., Rutschmann,J.: Eine Schnellmethode zur Bestimmung von Tritium, Radiokohlenstoff und Radioschwefel in beliebigem organischem Probenmaterial mittels des Flüssigkeits-Szintillationszählers. Helv. Chim. Acta 242, 1957 (1961). 
Kim,J.H., Gelbard, A.S., Perez,A.G.: Action of hydroxyurea on the nucleic acid metabolism and viability of HeLa cells. Cancer Res. 27, 1301 (1967).

- Perez,A.G., Djordjevic,B.: Studies on unbalanced growth in synchronized HeLa cells. Cancer Res. 28, 2443 (1968).

Krakoff,I.H., Brown, N.C., Reichard, P.: Inhibition of ribonucleoside diphosphate reductase by hydroxyurea. Cancer Res. 28, 1559 (1968).

Madoc-Jones, H., Mauro, F.: Age-responses to X-rays, vinca alkaloids and hydroxyurea of murine lymphoma cells synchronized in vivo. J. Natl. Cancer Inst. 45, 1131-1143 (1970).

Mauro,F., Madoc-Jones, H.: Age response to X-radiation of murine lymphoma cells synchronized in vivo. Proc. Natl. Acad. Sci (US) 63, 686 (1969).

- - Age responses of cultured mammalian cells to cytotoxic drugs. Cancer Res. 30, 1397 (1970).

Mueller,G.C.: Biochemical events in the animal cell cycle. Federat. Proc. 28, 1780 (1969).

Nery,R.: The colorimetric determination of hydroxamic acids. Analyst 91, 388 (1966).

Pfeiffer, S.E., Tolmach, L.J.: Inhibition of DNA synthesis in HeLa cells by hydroxyurea. Cancer Res. 27, 124 (1967).

Philips, F.S., Sternberg, S.S., Schwartz, H.S., Cronin, A.P., Sodergren,J.E., Vidal,P.M.: Hydroxyurea. I. Acute cell death in proliferating tissues in rats. Cancer Res. 27, 61 (1967).

Pilgrim,C., Lennartz,K.J., Wegener,K., Hollweg, S., Maurer,W.: Autoradiographische Untersuchungen über tageszeitliche Schwankungen des $\mathrm{H}^{3}$-Index und des Mitose-Index bei Zellarten der ausgewachsenen Maus, des Ratten-Fetus sowie bei Aszites-Tumorzellen. Z. Zellforsch. 68, 138 (1965).

Pollak, R.D., Rosenkranz,H.S.: Metabolic effects of hydroxyurea on BHK 21 cells transformed with polyoma virus. Cancer Res. 27, 1214 (1967).

Prescott,D.M.: Composition of the cell life cycle. In: Normal and malignant cell growth. Fry, R.J.F., Griem, M.L., Kirsten, W.H. (Eds.). Recent Res. in Cancer Res. 17. SpringerVerlag, Berlin-Heidelberg-New York, 79 (1969).

Quastler, H., Sherman,F.G.: Cell population kinetics in the intestinal epithelium of the mouse. Exp. Cell Res. 17, 420 (1959).

Rajewsky,M.F.: Synchronisation in vivo: Kinetics of mammalian cell populations following blockage of DNA synthesis with hydroxyurea. Abstr., IInd Meeting Europ. study group for cell proliferation (ESGCP), Schloß Reisenburg, Germany (1968).

- (1) Synchronisation in vivo: Kinetics of a malignant cell system following temporary inhibition of DNA synthesis with hydroxyurea. Exptl. Cell Res. 60, 269 (1970).

- (2) Temporal and metabolic aspects of tumor cell cycles. Proc. Xth Int. Cancer Congress, Houston (1970), Vol. I, p. 394. Year Book Med. Publ. Inc., Chicago.

- Fabricius, E., Hülser, D.F.: Synchronisation in vivo: Temporary inhibition of DNA synthesis in the rat embryo with hydroxyurea. Exp. Cell Res. 66, 489 (1971).

- Grüneisen, A.: In Vorbereitung.

Rosenkranz,H.S.: Some biological effects of carbamoyloxyurea, an oxidation product of hydroxyurea. J. Bacteriol. 102, 20 (1970).

- Carr,H.S.: Hydroxyurea and escherichia coli nucleoside diphosphate reductase. Cancer Res. 30, 1926 (1970).

- Jacobs, S.J.: Inhibition of DNA synthesis by hydroxyurea. Gann Monograph 6, 15 (1968).

- - Carr,H.S.: Studies with hydroxyurea. VIII. The deoxyribonucleic acid of hydroxyurea-treated cells. Biochim. Biophys. Acta 161, 428 (1968).

- Pollak, R.D., Schmidt, R.M.: Biologic effects of isohydroxyurea. Cancer Res. 29, 209 (1969).

Rueckert, R.R., Mueller,G.C.: Studies on unbalanced growth in tissue culture. I. Induction and consequence of thymidine deficiency. Cancer Res. 20, 1584 (1960).

Schwartz,H.S., Garofalo,M., Sternberg,S.S., Philips, F.S.: Hydroxyurea: Inhibition of deoxyribonucleic acid synthesis in regenerating liver of rats. Cancer Res. 25, 1867 (1965).

Shipley, W.U.: Immune cytolysis in relation to growth cycle of Chinese Hamster cells. Cancer Res. 31, 925 (1971).

Sinclair, W.K.: Hydroxyurea: Differential lethal effects on cultured mammalian cells during the cell cycle. Science 150, 1729 (1965).

- Cyclic X-ray responses in mammalian cells in vitro. Radiation Res. 33, 620 (1968). 
Sinclair,W.K.: Methods and criteria of mammalian cell synchrony. In: Normal and malignant cell growth. Fry, R.J.M., Griem, M.L., Kirsten,W.H. (Eds.). Recent Results in Cancer Res. 17. Springer, Berlin-Heidelberg-New York, 90 (1969).

Steel,G.G.: Unveröffentlichte Ergebnisse, persönliche Mitteilung (1969).

- Adams, K., Barrett,J.C.: Analysis of the cell population kinetics of transplanted tumors of widely-differing growth rate. Brit. J. Cancer 20, 784 (1966).

- Hanes, S.: The technique of labelled mitoses: Analysis by automatic curve fitting. Cell Tissue Kinet. 4, 93 (1971).

Stubblefield,E.: Synchronisation methods for mammalian cell cultures. In: Methods in cell physiology, Vol. III (Ed.: D. M. Prescott). Academic Press New York-London, p. 25 (1968).

Süss, R., Maurer,H.R.: Reduced binding of carcinogenic hydrocarbons to DNA of mouse skin during inhibition of DNA synthesis. Nature 217, 752 (1968).

Till,J.E., Whitmore,G.F., Gulyas, S.: Deoxyribonucleic acid synthesis in individual L-strain mouse cells. II. Effects of thymidine starvation. Biochim. Biophys. Acta 72, 277 (1963).

Thurman,W.G., Bloedow, C., Howe,C.D., Lewin,W.C., Davis, P., Lane,M., Sullivan,M.P., Griffith,K.M.A.: Phase I: Study of hydroxyurea. Cancer Chemotherap. Rpt. 29, 103 (1963).

Vesco,C., Penman, S.: Purified cytoplasmic DNA from HeLa cells: Resistance to inhibition by hydroxyurea. Biochem. Biophys. Res. Comm. 35, 249 (1969).

Yarbro,J.W.: Further studies on the mechanism of action of hydroxyurea. Cancer Res. 28, 1082 (1968).

Young, C.W., Hodas, S.: Hydroxyurea: Inhibitory effect on DNA metabolism. Science 146, 1172 (1964).

- Schochetman, G., Hodas, S., Balis, M.E.: (1) Inhibition of DNA synthesis by hydroxyurea: Structure-activity relationships. Cancer Res. 27, 535 (1967).

- Karnofsky,D.: (2) Hydroxyurea-induced inhibition of deoxynucleotide synthesis: Studies in intact cells. Cancer Res. 27, 526 (1967).

Priv.-Doz. Dr. M. F. Rajewsky

Dr. D. F. Hülser

Cand. med. E. Fabricius

Max-Planck-Institut für Virusforschung

Abteilung Physikalische Biologie

D-7400 Tübingen, Spemannstr. 35

Deutschland 